\title{
Resources for social development
}

Working Paper No. 21

Anthony Clunies Ross

Policy Integration Department

World Commission on the Social Dimension of Globalization

International Labour Office

Geneva

May 2004

Working papers are preliminary documents circulated

to stimulate discussion and obtain comments 
Copyright (C) International Labour Organization 2004

Publications of the International Labour Office enjoy copyright under Protocol 2 of the Universal Copyright Convention. Nevertheless, short excerpts from them may be reproduced without authorization, on condition that the source is indicated. For rights of reproduction or translation, application should be made to the Publications Bureau (Rights and Permissions), International Labour Office, CH-1211 Geneva 22, Switzerland. The International Labour Office welcomes such applications.

Libraries, institutions and other users registered in the United Kingdom with the Copyright Licensing Agency, 90 Tottenham Court Road, London W1T 4LP [Fax: (+44) (0)20 7631 5500; email: cla@cla.co.uk], in the United States with the Copyright Clearance Center, 222 Rosewood Drive, Danvers, MA 01923 [Fax: (+1) (978) 750 4470; email: info@,copyright.com] or in other countries with associated Reproduction Rights Organizations, may make photocopies in accordance with the licences issued to them for this purpose.

ISBN 92-2-116011-4 (printed version)

ISBN 92-2-116012-2 (web version)

First published 2004

Cover:

The designations employed in ILO publications, which are in conformity with United Nations practice, and the presentation of material therein do not imply the expression of any opinion whatsoever on the part of the International Labour Office concerning the legal status of any country, area or territory or of its authorities, or concerning the delimitation of its frontiers.

The responsibility for opinions expressed in signed articles, studies and other contributions rests solely with their authors, and publication does not constitute an endorsement by the International Labour Office of the opinions expressed in them.

Reference to names of firms and commercial products and processes does not imply their endorsement by the International Labour Office, and any failure to mention a particular firm, commercial product or process is not a sign of disapproval.

ILO publications can be obtained through major booksellers or ILO local offices in many countries, or direct from ILO Publications, International Labour Office, $\mathrm{CH}-1211$ Geneva 22, Switzerland. Catalogues or lists of new publications are available free of charge from the above address, or by email: pubvente@ilo.org

Visit our website: www.ilo.org/publns

Printed by the International Labour Office, Geneva, Switzerland 


\section{Resources for social development}

\section{Contents}

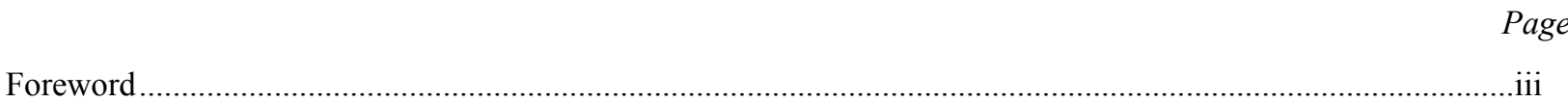

Preface

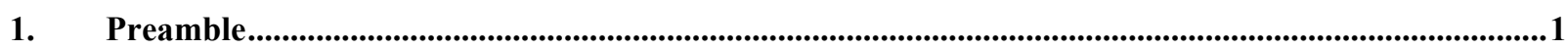

1.1 Priority: a quantitative additional funding target for high-priority global purposes ..................... 3

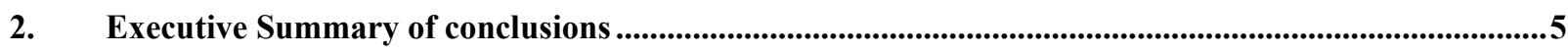

$2.1 \quad$ Resources mobilized by and for internationally coordinated action ..........................................5

2.2 Resources available to and through national governments ....................................................... 11

2.3 Resources available to and through local governments ........................................................... 12

$2.4 \quad$ Resources available through community mobilization............................................................... 12

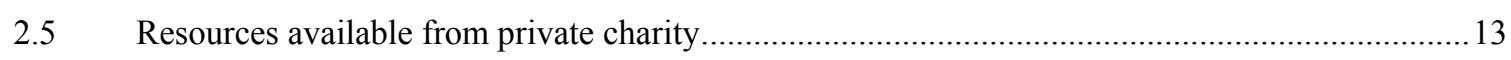

2.6 Resources available from commercial enterprises................................................................. 13

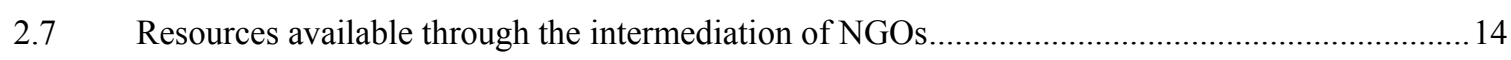

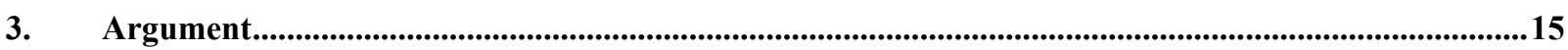

3.1 Resources mobilized by and for internationally coordinated action ....................................... 15

3.1.1 Why internationally coordinated action may be necessary ........................................ 15

3.1.2 Why not rely simply on an equitable system of governmental contributions? ................16

3.1.3 Factors that may reduce the political cost............................................................. 17

3.1.4 The prior question: How the funds will be applied? ..................................................... 17

3.1.5 Candidates with a case for reducing the political pain of providing extra revenue for global purposes.............................................................................. 18

3.2 Resources available to and through national governments .....................................................42

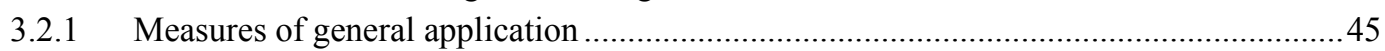

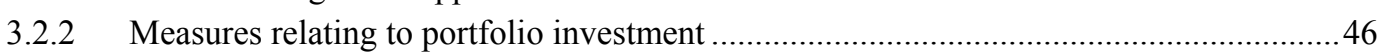

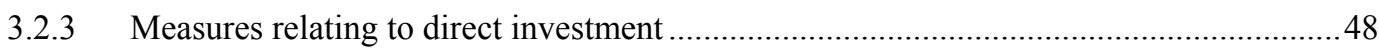

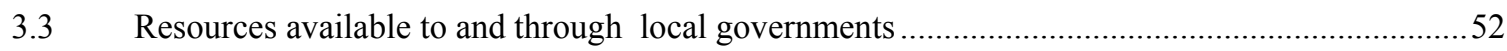

3.3.1 Betterment levies on property owners ....................................................................... 52

3.3.2 Developers' contributions to social infrastructure ........................................................53

3.4 Resources available through community mobilization ...............................................................5

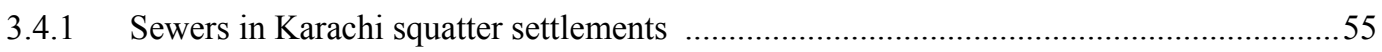

3.4.2 Water management in a Sri Lankan irrigation project..............................................55

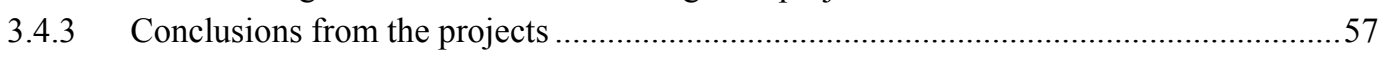

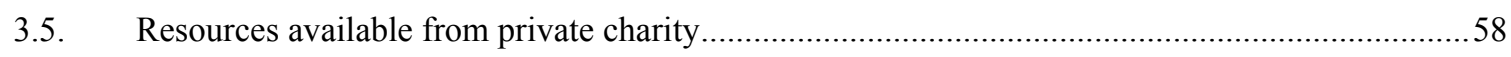

3.6 Resources available from commercial enterprises...........................................................60

3.6.1 Pre-commitments to providing markets for the products of private research and development.

3.6.2 Subsidy to reduce the price of patented drugs (or other inventions) without reducing the incentives to $R \& D$.

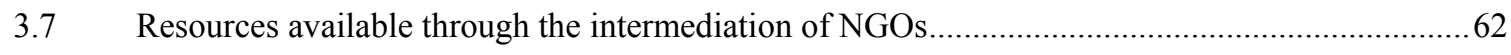

Bibliography 



\title{
Foreword
}

In February 2002, the ILO established an independent World Commission on the Social Dimension of Globalization, co-chaired by President Tarja Halonen of Finland and President Benjamin Mkapa of Tanzania and comprising 26 eminent commissioners from a wide range of walks of life and different parts of the world, each serving in their individual capacity. Its broad goals were: to identify policies for globalization that reduce poverty, foster growth and development in open economies, and widen opportunities for decent work; to explore ways to make globalization inclusive, so that the process can be seen to be fair for all, both between and within countries; to promote a more focused international dialogue on the social dimension of globalization; to build consensus among key actors and stakeholders on appropriate policy responses; and to assist the international community forge greater policy coherence in order to advance both economic and social goals in the global economy.

The report of the World Commission, A fair globalization: Creating opportunities for all, was released on 24 February 2004. It is available on the Commission's website www.ilo.org/public/english/wcsdg/index.htm.

A secretariat was established by the ILO to support the Commission. Among other tasks, it compiled information and commissioned papers on different aspects of the social dimension of globalization. The aim was to provide the Commission with documentation and data on a wide range of options and opinions concerning subjects within its mandate, without committing the Commission or individual Commissioners to any particular position on the issues or policies concerned.

Material from this background work is being made available as working papers, as national and regional reports on meetings and dialogues, and in other forms. Responsibility for the content of these papers and publications rests fully with their authors and their publication does not constitute an endorsement by the World Commission or the ILO of the opinions expressed in them.

\author{
Gerry Rodgers \\ Director \\ Policy Integration Department
}





\section{Preface}

The Technical Secretariat to support the World Commission on the Social Dimension of Globalization first prepared a synthesis of ILO activities on the Social Dimension of Globalization (published as Working Paper No. 1 in this series). Documentation on the work and outcomes of other major commissions, an ideas bank, a database and knowledge networks of experts and social actors were subsequently developed. These networks have dealt with several topics, including: inclusion at the national level for the benefits of globalization to reach more people; local markets and policies; cross-border networks of production to promote decent work, growth and development; international migration as part of the Global Policy Agenda; international governance (including trade and finance); the relationship between culture and globalization; and values and goals in globalization. Gender and employment aspects were addressed throughout this work. The Reports on the Secretariat's Knowledge Network Meetings are available on the Commission's web site or in a special publication from the ILO (ISBN 92-2-115711-1).

During the course of these activities, a number of substantive background papers were prepared, which are now made available for wider circulation in the Policy Integration Department's Working Paper series (Nos. 16 to 38), as well as on the Commission's website.

In his paper Professor Clunies Ross of the University of Strathclyde, concentrates on various ways of mobilizing resources for social and economic development, which are technically and administratively accessible, are unlikely to impose any unduly high excess burden of costs through misallocation, are regarded as equitably distributed, are not politically out of the question and are so far not fully exploited or not exploited at all. The discussion in the paper goes well beyond methods of taxation, important as these are, and considers some ways in which public policy and private non-commercial activity might serve to direct resources to social and economic development

Prof. Clunies Ross considers the feasibility of the following set of resources

- Resources mobilized by and for internationally coordinated action.

- $\quad$ Resources available to and through national governments.

- $\quad$ Resources available to and through local governments.

- Resources available through community mobilization.

- Resources available from private charity.

- Resources available from commercial enterprises.

- $\quad$ Resources available through the intermediation of NGOs.

\section{Rolph van der Hoeven \\ Manager, Technical Secretariat \\ World Commission on the Social Dimension of Globalization}

May 2004 


\section{Resources for social development}

1. Preamble

"Globalization" is a term that can be used to cover a wide variety of phenomena involving changes of various kinds. Some of these changes are effectively irreversible or even irresistible. Some may be blocked or modified. Some create or exacerbate obstacles to social development or specifically to the mobilization of resources for social development. Some may provide new opportunities. The devices considered here will relate in a variety of ways to the processes covered by globalization.

Regardless of where exactly the boundaries of "social development" are drawn, its deliberate promotion on behalf of the public clearly requires resources. The elements of social and economic development (however precisely defined) interact, as both do also with peacekeeping and peacemaking and the enforcement of human rights. The Millennium Development Goals (MDGs), a set of social and economic objectives formally adopted by the United Nations General Assembly on behalf of the world community to be fulfilled by the year 2015, will require, according to a World Bank estimate, an additional US\$30-70 billion a year in public spending. The Zedillo High-Level Panel of 2001 gave estimates of the extra resources needed that seemed to imply a total of US\$65 billion a year. These estimates are of the general order of magnitude of the total Overseas Development Assistance (ODA) currently provided by the high-income countries and multilaterals, which amounts to roughly US $\$ 50$ billion a year. There are various ways, apart from straight public finance, by which resources can be provided to fuel the pursuit of social and economic development; and the funds involved need not always pass through the budgets of governments or official multilateral bodies. But, whatever the other channels for funding and the other necessary conditions, extra finance of at least this general magnitude - in the hands of public authorities and likely to be applied to endeavours of top world priority - seems likely to be necessary if such rudimentary approaches to the demands of social justice as those entailed by the Millennium Development Goals are to be reached by 2015 .

Public funds might be generated by global institutions or arrangements, or by national or local governments. Funds or other resources might be made available for social and economic development by social mobilization, or by government incentives to commercial entities, or from private philanthropy, or from various sources through the intermediation of non-government organizations (NGOs).

This paper will concentrate on various ways of mobilizing resources for social and economic development that appear to have all the following characteristics:

(a) They are technically and administratively accessible.

(b) Their collection, or their diversion to social development, is unlikely to impose any unduly high excess burden of costs through misallocation, or may even be favourable in its allocative effect, or may itself be a by-product of the procurement of some public good. 
(c) If they are designated to be used for development needs of high social priority, any burden imposed by their collection or mobilization can be regarded as equitably distributed.

(d) They are not politically out of the question obviously, ineluctably, and forever.

(e) They are so far not fully exploited or not exploited at all.

A few that do not match all these requirements will be mentioned, but rather to emphasize their weaknesses.

The subject matter will go well beyond methods of taxation, important as these are, and consider some ways in which public policy and private non-commercial activity might serve to direct resources to social and economic development, or at least to mobilize additional socially available resources that might be so directed.

The methods considered will be divided in the following way:

- Resources mobilized by and for internationally coordinated action. This will consider methods of taxation that appear to have a particular comparative advantage (technical or moral or political) for cooperative international imposition and application, or can be associated with the procurement of global public goods. It will also consider the use of SDR creation as a source of funds for social and economic development: a possible by-product of its application in world economic stabilization.

- Resources available to and through national governments. Here the subject will be ways of minimizing certain opportunities of avoidance and evasion of taxes, and competitive pressures to reduce tax rates or bases. These are the opportunities and pressures created by the existence of independent national tax jurisdictions in a world of extensive transnational enterprise and capital movement. They apply particularly to taxes on the earnings of capital and enterprise. The devices considered for limiting these opportunities will be generally to the fiscal advantage of all jurisdictions (with the possible exception of some of those deriving a large part of their income as a direct result of specializing as tax havens), but proportionately they will probably bring most benefit to the revenues of developing countries.

- Resources available to and through local governments. This will consider betterment levies on property owners (to capture a share of the increased value created for them by social investment), and charges to new investors for the cost of the social infrastructure that their investment will entail. In favour of these devices is their economic efficiency and the strong moral case that can be made for them.

- $\quad$ Resources available through community mobilization. Voluntary labour, care, and ingenuity may be made available free of charge to community projects if an initial vision and trust can be created and structures set up which ensure that contributions are not wasted, that all participants are likely to benefit, and that there is universal participation by contributor-beneficiaries in control of the ventures. Two striking, and relatively large-scale, examples will be cited.

- Resources available from private charity. This will be used to explore the possibilities of multisectoral global funds (MGFs) as a way of attracting funds from private benefactors and charitable foundations - together with expertise from a number of sources towards their useful employment - to the pursuit of global common purposes of high social priority.

- Resources available from commercial enterprises. Where extremely costly research is needed to produce critical technical advances, as over drugs and vaccines 
against some of the main endemic diseases - largely for the benefit of people in countries with low purchasing power - public guarantees, to the relevant firms, of markets for products meeting certain requirements may be a way of giving extra leverage to the public resources available. Compromises involving an element of subsidy may also be the most efficient means of allowing drugs within the period of patent protection (or generic equivalents) to be sold in developing countries at close to production cost, without reducing incentives to research and development (R\&D).

- Resources available through the intermediation of NGOs. Among their many functions, non-commercial NGOs appear normally to be needed as a vital element in the efficient and sustainable provision of microcredit for productive purposes where the clientele consists largely or exclusively of poor people.

\section{$1.1 \quad$ Priority: a quantitative additional funding target for high-priority global purposes}

In the seven sections that follow, a large share of attention is given to the subject of the first, which deals with possible methods of raising funds that could be used with some degree of global coordination for the purpose of meeting key social objectives - such objectives as those enumerated in the Millennium Development Goals.

The pretexts for the concern for global coordination are: (a) that some of these objectives have a (global) public good character, either intrinsically (as in the attack on tuberculosis) or because world opinion treats them as common concerns (as in the provision of clean water for all); (b) that there are doubts about the capacity of a number of countries unaided to achieve the targets within their borders even where there are not considerable cross-border externalities; and (c) that overseas development assistance (ODA) dispensed by individual donor countries often (especially when the donors are major powers) has a mixture of motives, and needs coordination if it is to achieve what world forums, when they attempt to speak for the human family, deem to be the highest social and economic priorities. The case is set out more fully in section 3 below, under the sub-heading "Why internationally coordinated action may be necessary".

A need of this kind has been recognized in the setting up of certain global funds for special purposes, such as the Global Fund for fight AIDS, Tuberculosis, and Malaria (GFATM); the Vaccine Fund associated with the Global Alliance for Vaccination and Immunity; and the UN Environmental Facility. These may be, as in the first two cases, formally outside both the UN family and the multilateral financial institutions (MFIs). Their constitutions have been devised ad hoc to meet the political constraints of the times in which they have emerged. They have arisen to meet either large new needs (such as that of dealing with AIDS and the resurgence of tuberculosis that has come with it, or earlier of assisting with the costs of ozone-layer protection) or a renewed sense of urgency over pre-existing needs (such as universal vaccination of children against certain diseases). By the standard of the needs assessed, the first of these funds (the most recent) appears likely initially to be greatly under-financed. Its funds have been sought by appealing to governments for voluntary contributions without any agreed basis for the individual scales of the amounts required.

If there is to be much political impetus to a substantial mobilization of additional funds, to be available under some degree of global coordination, for global purposes, it seems likely that there will first have to be a widely-advanced quantitative target. A well-publicized and 
well-attested number, backed by a precise account of how it has been reached and what it represents, may provide a rallying-point, and perhaps channel to useful ends some of the genuine informed concern that has become mixed with windmill-tilting and nihilism in the campaign against globalization. Faced with a sustained, rational campaign for a particular quantitative target, the decision-makers may be more inclined to look seriously at possible ways of attaining it. Then the least politically embarrassing of the financing options and of the ways of administering the funds raised may acquire an attraction.

We suggest that the World Commission on the Social Dimension of Globalization take as part of its agenda the task of producing such a target, with the hope of having it endorsed by a selection of individual people who count as world moral leaders, and perhaps also of others recognized as possessors of an unusual degree of worldly wisdom; and by the NGOs campaigning for development, peace, and justice (these people and organizations would need to be informed in advance of the process being undertaken to define such a target, and to be consulted for their opinions while the discussion was proceeding). The aim might be thereafter to have the target endorsed by the UN General Assembly and by as many governments and parliaments as possible.

There are three requirements for this use of a target:

- $\quad$ First, there would need to be a decision about the issues proposed to be covered by the additional funds. For political reasons, the manifest human importance of particular needs - combined with the obvious relevance of known methods for dealing with them - might have in part to dictate the selection. The list might, for example, be confined to certain infectious diseases; primary education; accessible clean water; and urban sewerage. Arbitrary decisions would be needed, but with some rationale, such as that these were matters of very high welfare priority that for many countries would generally not be fully and satisfactorily covered out of domestic resources and IBRD-type or even IDA-type loans and that they would be sufficiently clear-cut for their backstopping through international assistance to be "campaignable". Such a list would be clearly related to the Millennium Development Goals but there would be no need for it to be rigorously dictated by them.

- A second necessary exercise would be to make as clear as possible what should qualify as fulfilment of the funding target. The funds would need to be recognizably additional, whether to national ODA or to the budgets of multilateral organizations; and they would need to be devoted, in a broadly coordinated way, to the goals and issues specified. A degree of precision would be a further requirement of productive campaignability.

- A third requirement would be to do, for each of the other issues to be covered, something analogous (though probably more cursory) to the task performed for health needs by the Report of the Commission on Macroeconomics and Health (World Health Organization, 2001), giving projections to 2015 of total requirements for the purpose in the low-income and selected middle-income countries covered; of the part of this targeted to be covered domestically; and consequently of the residue to be covered by global subsidy. Estimates provided by the World Bank for the Monterrey Financing for Development meeting of 2002 might be used as a basis, especially if it were possible to discover how they were reached and consequently to seek rational grounds for affirming them, selecting values within the range that they give, or modifying them. By this means an annual series of total required additional contributions could be made. Since it would be reasonable to expect this to rise in nominal and real terms as world income grew, it would probably be appropriate for it to be trimmed and adjusted so that it could be expressed, for example, as a fixed 
proportion of world gross product in conventional foreign exchange dollar terms, say 0.2 per cent or 0.3 per cent. This would not preclude having a headline figure, say for 2005 in 2005 US dollars, which could be used as the initial public target.

This proposal is repeated in brief at the start of the Executive Summary.

\section{Executive Summary of conclusions}

\subsection{Resources mobilized by and for internationally coordinated action}

Globally coordinated action, frequently requiring funding, is needed not only for providing what are strictly and intrinsically global public-goods but also for achieving objectives that are considered essential on grounds of social-justice, solidarity, or compassion.

It is suggested here, for the purpose of generating a climate of opinion on which any use of the devices considered in section 1 may well depend, that the Commission should propose a quantitative target in the form of an annual amount or series for additional international public-sector funding of certain high-priority global purposes; should express this target in "campaignable" form; and should take action through which the target achieves wide public attention and becomes a subject of campaigning:

(a) The purposes for which these additional funds might be used should be proposed; with

(b) a clear definition of what precisely should be regarded as fulfilment of the target; and

(c) an explanation of how the target is derived.

Funding for these purposes might take the form of: (i) coordinated direction of additional bilateral overseas development assistance; or of (ii) extending the system of equitable contributions by governments that funds a number of international organizations. But, because of the political difficulties facing any substantial further accession of funds by these means, we look for (iii) other ways in which funds might be globally generated, ways that might win the cooperation or consent of the world's governments because they reduced the political cost that would be associated with the budgetary provision by individual governments of additional bilateral ODA or of additional contributions to international entities assessed in accordance with ability to pay.

Four possibly relevant factors that might cause the political cost to be lower than would be the case with a straight additional appropriation for global purposes, or a new run-of-themill domestic tax or tax increase, are the following:

(i) The revenue devices or appropriations, and their incidence and local opportunity cost, are not highly visible.

(ii) The political cost and effort of framing tax or appropriation measures and piloting them through the legislature are obviated.

(iii) The collection of the revenue is itself linked to the achievement of some widely desired end, such as a recognized global public good, so that two birds can be killed with one stone. 
(iv) Any national cost of delivering the revenue is clearly, perhaps even structurally, tied to a world effort, so that there is little or no risk of having to carry free-riders.

Revenue devices are not likely to be appealing unless they meet one or more of these tests. We call them the visibility, effort, two-birds, and free-rider tests respectively.

A generally approved system for management and allocation of the sums raised must also be a precondition of any acceptable coordinated scheme of raising revenue for global purposes; and some outline of possible arrangements of this kind needs to accompany the promulgation of a target or the promotion of any device for attaining it.

Six apparent candidates for revenue devices are considered here. Only the last four have useful immediate prospects, but at least two of these are intrinsically promising.

\section{(i) Arms trade taxes}

- Taxing the legitimate arms trade would largely involve taxing by governments of themselves.

- Proportionately to income, the burden of a uniform tax would quite possibly fall most heavily on poorer countries, so that internationally the tax might well be highly regressive in its incidence. Together, this and the previous characteristic probably render it out of the question politically.

- Revenue would be highly unreliable.

The tax would not satisfy the invisibility test or the free-rider test. It would go some way to meeting the effort test - in so far as it could be collected if either all exporting countries or all importing countries imposed it. It would arguably meet the two-birds test, though the effect might be rather to burden the budgets of a number of poor countries than to decrease their arms purchases.

On the most favourable assumptions, it would be a modest revenue-earner by the standards of interest here: around US\$5 billion in a recent year from a 25 per cent tax, on the supposition of no compensation to low-income losers and zero price elasticity of demand.

\section{(ii) Taxes on the resource rents of deep-ocean minerals}

- Taxing the resource-rents of deep-ocean minerals for global purposes is exemplary on grounds of equity and could be done in a manner that was economically efficient.

- Moreover, its use for global purposes has been agreed, and a skeleton institutional structure has been created for doing it.

- The device would be virtually free of political pain. It would meet all the tests.

- But the activity to be taxed does not yet exist.

\section{(iii) Taxes on international air transport}

- An international air-transport tax could be easily and reliably collected.

- It would provide a buoyant source of revenue over the longer term. 
- An environmental case can be made for it, though the case could be made more convincingly for a tax on all air transport.

- The burden of the tax on users would on the whole be progressively distributed, both internally and internationally.

- $\quad$ But the burden on suppliers would bear particularly hard on countries specializing as tourist destinations, which are often poor with few alternative exploitable resources and might need compensation.

* Of the criteria for reducing political pain, it could meet only the two-bird test, and that uneasily.

Without any allowance for compensation, and with complete coverage and the highest rates likely to be tolerated, revenue is unlikely to be above US\$20 billion.

\section{(iv) A tax on carbon-use or equivalent}

- A uniform carbon tax would be cheap and easy for national governments to impose and collect, but, if it were to be a genuinely universal additional charge impinging on every user of hydrocarbon fuels, the 200-odd governments of the world would need to cooperate in legislating for it and administering it.

- Its allocative effect would be favourable, tending if anything to compensate for one of the major global environmental externalities now causing concern - and all the more so if (not impossibly) it were to be combined with equivalent taxes on other greenhouse activities.

- A possible variant is that the governments should simply commit themselves to deliver internationally the equivalent of the proceeds of a carbon or carbon-equivalent tax of so much per unit, though this would remove much of the tax's attraction on environmental grounds.

- $\quad$ Supposing over the relevant range an elasticity of demand close to zero; then at rates of tax that would be small in relation to the price changes frequently experienced in the market - rates that would be little noticed by final consumers in rich countries - a carbon tax universally enforced could raise revenue for global purposes amounting to roughly 2.5 times current ODA; one on high-income countries alone, perhaps 1.2 times.

- $\quad$ Failing other much more drastic changes, taxation at these rates would at most lower the path, and perhaps reduce somewhat the trend rate, of increase of hydrocarbon use; so that revenue in most years would still rise.

- However, across countries the burden of the tax would be far from proportional to income. Some poor countries would be delivering in revenue a higher, occasionally a much higher, proportion of income than some of the rich.

- And the countries specializing in hydrocarbon production, while they might not suffer seriously as a result of the rates of tax suggested, might well be opposed.

- On both grounds there might well be political obstacles to the universal application of the tax. 
- However, if even the high-income countries alone (excluding the handful of small oil specialists among their number) imposed the tax at the very low rate contemplated and delivered the proceeds internationally, funds resulting would exceed current ODA. And imposition by high-income countries at say twice these rates, with still probably little immediate erosion of the tax-base as a result, would not be out of the question.

- But, of the four criteria of political-pain-reduction, this device would meet only the two-bird test, and the case for it on that ground in practice would probably rate as thin.

\section{(iv) A currency transaction tax (CTT)}

It is supposed here that the tax is collected not by fiscal departments on currency trades as and where they are agreed to, but rather by monetary authorities on trades in their respective currencies at the points at which those trades are settled within their own banking systems. The tax is thus collected by each authority from foreign exchange banks under its jurisdiction and from offshore netting systems as a condition of access to its banking system. Because virtually all wholesale currency transactions have one of a few vehicle currencies on one or both sides, virtually complete tax cover of wholesale transactions can be achieved through the cooperation of the five or so authorities issuing those vehicle currencies. Modern settlement systems allow them to identify the total volumes of gross transactions in their currencies.

- The tax would be imposed on a base that is so far largely unexploited for revenue purposes.

- Collection by the method suggested here - on bank settlement of transactions - would be cheap and could readily be made watertight.

- Universal application would require the active cooperation of only five authorities, though it would be a useful precaution for perhaps eight others to agree to take part if need should arise.

- So, for the rest of the world, it would satisfy the effort test, and, because of the small number of active participants needed, it would go far towards satisfying the free-rider test.

- Though there has in the past been intense and emotional opposition to the tax in some influential United States circles, the fact that the system of collection suggested here would give the United States effectively a day-to-day veto over the means of disposal of the revenue might be used to mitigate this opposition insofar as it had a rational element.

- The revenue from this tax - however collected, but most obviously with the method suggested here - would in a moral/political sense have a special comparative advantage for international use, since the burden would be widely spread across both rich and poor countries, whereas those that would be collecting it would be rich countries, and, even among these countries themselves, the revenue collected would bear little or no relationship to the burden borne. So its retention by the governments that collected it would be highly objectionable.

- It is generally taken that any adverse allocative effects of the tax at the rates usually discussed - generally 0.1 per cent or less, or at most 0.25 per cent - would be negligible. Even if the increase in transaction costs on such "real" international dealing as trade, remittances, and long-term investment amounted to say 4 or 5 times the rate of the tax itself, the impact would not be great (it seemed best here to ignore 
the question whether such very low revenue rates of CTT, applied universally - as distinct from ad hoc uses of a CTT for stabilization purposes - would have a favourable or an adverse effect on the stability of exchange rates).

- The burden of the tax could be seen as having two main elements. Its distribution between the two would be hard to guess and would depend, among other elements, on rates of tax and how far the volume of transactions responded to them. One part could be expected to fall on the finance industry - because, even though the tax would be "passed on", any reduction in volume of transactions would tend to reduce the earnings in this sector. This part of the burden would be concentrated in rich countries. The other part would fall on the populations of all countries in rough proportion to their engagement in "real" international (or at least inter-currency area) transactions (trade, transfers/remittances, and long-term investment). This latter part would be only roughly proportional to income, with the more "open" economies at any income level tending to bear a larger share. But, given the concentration of the finance industry part of the burden in rich countries, the burden would probably tend overall to be progressive in relation to income across countries.

- It would be a political advantage that the burden, apart from that part falling on the finance industry, would be diffuse and not readily identified. So, for a huge majority of people in every country, the device would meet the invisibility test. But the probable opposition of those within the finance industry, who as a group are influential, would be an obstacle.

- Because we have no clear idea of the reaction of the currency markets to the tax, and hence also no clear idea of what rate of tax would generate most revenue, or above what rate the addition to transaction costs in trade, remittances, or investment would come to have a significant effect on those "real" transactions, it would be best to apply the tax experimentally at a very low rate, and then to raise it by small increments - in order to record the effects on the volume and total cost of transactions while simultaneously studying the markets in order to explain whatever changes were observed. Trial and error, combined with increasing understanding, might eventually allow a point to be reached at which an informed judgment could be made over desirable rates.

- It has been suggested, on the basis of some analysis of the currency-market institutions, that a rate of 0.02 per cent would have very little impact on the volume of transactions. This might be a good experimental starting rate. If it in fact had no impact on volume, it could be expected to raise about US\$53 billion on the volume estimated for the year 2000. This would be roughly equal to annual ODA. Other informed guesses made recently about responses would, if applied to the year 2000 aggregate, give US\$172 billion for a 0.25 per cent tax and US\$123 billion for a 0.1 per cent tax, respectively about 3.5 times and 2.5 times ODA.

* Revenue at any given rate might not be very reliable from year to year. Though the aggregate of transactions, as recorded in the latest estimates, had risen unremittingly until 1998, it appeared to fall by about 27 per cent between then and 2000 . 


\section{(vi) Creation of Special Drawing Rights (SDRs)}

* Political moves and informal bargains that seem not completely beyond the range of possibility over the next few years, and do not require the negotiation of further constitutional changes in the IMF, could start the process of implementing a scheme such as Soros proposes by which regular issues of SDRs could be resumed and the high-income countries could make over their allocations to a fund for global purposes.

- The regular SDR allocations could themselves be of value to a number of developing countries that felt the need of enhanced safety margins in their reserves. They would find SDRs a low-cost way of meeting this need - indeed a costless way until they actually disposed of the extra reserves so generated.

- Resumption of SDR allocations on a scale that could be justified by objectives to which the IMF is already constitutionally committed, and would steer a middle course between running down the volume of dollars and other currencies held in reserves and relying on its unlimited expansion, might generate, if there were complete compliance by the high-income members in the commitment of their allocations to global purposes, resources for the global fund initially of the order of US\$7580 billion a year.

- Under present arrangements, these funds available for global purposes would in effect be available for spending or transfer as termless loans at standard (Treasury Bill type) short-term interest rates, rather than as grants.

* However, these could be particularly useful to a global fund as reserves held against contingencies, such as having to make good a guarantee to provide a market for new medicines or vaccines meeting certain conditions. Another possible use would be to relieve the debts of certain countries by exchanging them for termless obligations at lower rates.

- $\quad$ Formalizing any such arrangement for contributing to a global fund, however, which could also go along with more flexible use of SDR creation for stabilization purposes, would require further amendment of the International Monetary Fund's (IMF) Articles of Agreement.

* Politically the device would meet the invisibility and two-birds tests, and also largely (in certain possible forms completely) the effort test and the free-rider test. So the opposition that proposals of this kind face in a few key countries may be transient.

* Yet, unless and until some other form of SDR or equivalent is invented that is more like a regular currency (or gold), the interest obligation that must be presumed to attach to SDRs 'passed on' (otherwise unrequited) from their original recipients limits their value for global funding and probably suggests that at least some other device in addition should be tapped as a source. 


\section{Resources available to and through national governments}

This section considers ways of stemming the leakages in national revenue systems that come about through the international mobility of capital and enterprise.

- Loss of revenue attributable to interaction among uncoordinated tax jurisdictions probably amounts, for developing countries, to sums at least of the order of total ODA, and, for OECD countries, to much more.

- The losses can be attributed to a combination of evasion, avoidance, and competitive tax degradation.

- The remedies lie in various reforms of legislation and practice, especially in the directions of transparency in financial institutions, exchange of information among tax authorities, removal of tax preferences to non-residents, and application of the credit principle by residence jurisdictions in allowing for tax exacted elsewhere. Pressure and persuasion in these directions is being applied by the OECD and other associations.

- However certain measures that might be taken by particular countries and groups of countries now would accelerate these reforms, or compensate for their present deficiencies, or provide leads for pursuing them more thoroughly and effectively, and in some cases might make large inroads quickly into the revenue losses. These include the following.

- A withholding tax at a reasonably high rate (40 per cent or more) might be applied by all cooperating countries to interest, royalties, management fees, and dividends payable to non-residents, remittable in full to all (other than residents of countries covered by tax treaties with the source country) who could give evidence that the income concerned had been notified to the authorities in their countries of residence, and remittable as appropriate where there were tax treaties. This measure might be difficult to introduce without substantial agreement among the countries hosting the world's main financial centres. But moves recently made within the European Union suggest that the bulk of the Organization for Economic Co-operation and Development (OECD) countries might now be prepared to negotiate among themselves the implementation of such a measure.

- There might be agreement among tax authorities, as widely as possible: (a) to reform their taxation of the enterprise income of multinationals so that each firm would be required to file a return of its whole world income to each jurisdiction in which it was liable for tax; and (b) to negotiate a simple formula, based on a few objective and readily verified variables, for determining the proportions of the total income that would be subject to taxation in each jurisdiction. This reform might be led by a few OECD countries or worked out in a forum such as the OECD. The United States has strong apparent gains to be made from such a reform, as doubtless do many other countries.

- As a radical measure that might be approved by an international forum as allowable for its specific purpose: any country A might apply, to any firm $F$ that had its headquarters and site of production elsewhere and was selling within A's borders, a withholding tax at A's own corporate-tax rate on the gross value of F's sales within A. It would be a proviso that: (a) the tax should be remitted in full if $\mathrm{F}$ could show that it was not receiving, in any country of production or 
headquartering, income-tax preferences as an alien or non-resident; or, failing that requirement, that, (b) if $\mathrm{F}$ filed in $\mathrm{A}$ a full return of the income associated with its sales in A, the excess of the withholding tax over the income tax due, at A's rates, on that income would be remitted. Any substantial OECD country could apply this device without the need to fear adverse consequences, since multinationals would certainly continue to sell within its borders regardless; and its progressive implementation by countries constituting the bulk of the world market could be expected eventually to eliminate tax regimes giving preferences to non-residents and hence remove a large part of the problem of competitive tax degradation.

* A world forum or a significant group of governments might work out a single system of tax identification numbers through which individuals' or corporations' income-tax information could be shared among tax authorities without unnecessarily identifying the individuals or corporations involved and in such a way that the information could be kept anonymous in case it leaked into unauthorized hands. Each number would include indicators of all the jurisdictions in which the owner had tax liability. A person would be required to reveal her, his, or its number to any tax authority that had reason to think that it had claims on the person. Such a system could be adopted gradually as various countries recognized its advantages.

\section{Resources available to and through local governments}

- There is often scope for additional efficient and equitable ways of raising local government revenue (especially in towns) through: (a) systematically charging property owners for the increases in site value of their property that arise through planning decisions; and (b) charging prospective developers for the probable costs of the additional social infrastructure that their investments can be expected to require.

- Transparency and the minimization of administrative costs in the implementation of these measures depend upon the use of simple, standardized rules for determining the charges in each case: for example, standard rates per unit area for the rise in site values, each applying over a significant area; and standard costs of additional social infrastructure entailed by any type of investment, with, say, a coefficient particular to the kind of investment (housing, offices, sport, entertainment, retail, hospitality) applied to the amount invested.

\subsection{Resources available through community mobilization}

- There are large potential gains to be made, both material and immaterial, if some of the kinds of social facilities normally delivered and run hierarchically by governments or by large firms can instead be substantially generated and managed through unpaid labour and enterprise provided cooperatively by the people who will benefit from the facilities. 
* It is important in such cases that all the provider-beneficiaries have the opportunity and encouragement to participate in control.

- Because such cooperative participation generally requires face-to-face contact within each controlling or managing group, large projects of this sort are likely to need a "nested" or federal structure.

- Government may contribute in these cases by being ready to give the necessary permits; by authorizing official cooperation; often by supplying some critical input; and by regular contact with NGOs that have the potential for sparking such ventures.

\subsection{Resources available from private charity}

Multisectoral global funds (MGFs) are funds set up to serve global purposes, in which the public sector (national or multilateral) and the private sector (commercial or non-commercial or both) are jointly involved as controllers or donors or both.

* Applied to suitable purposes, MGFs may have the potential for attracting large private fortunes - to combine with multilateral, government, and other funds - for the sake of decisive attack on some of the world's major definable deficiencies, such as of disease control, literacy, or water supply.

* Characteristics that seem most likely to be attractive to the holders of big fortunes are: objectives that are easily quantified; operations with well-tried techniques that depend heavily for success on simple funding and logistics; and prospects of visibly momentous achievements within a decade or two.

* A major challenge for MGFs is to reach a form of constitution that allows all major stakeholders to have influence; that makes it possible to draw on the various sources of relevant expertise; and that nevertheless gives scope for leadership and consistent direction.

\section{Resources available from commercial enterprises}

- Research and development of vital interest to poor countries might sometimes be most efficiently and effectively generated, especially in the health field, with the help of a precommitment on the part of a public authority to provide a market of a certain size at a certain price to a firm that could offer for sale a product meeting stated criteria of effectiveness and price.

* Sometimes a subsidy on the sale of patented drugs in poor countries on condition that they are sold at a price close to the marginal cost of production might be the most cost-effective way of providing the drugs to people who need them without impairing the incentives to research and development. 


\subsection{Resources available through the intermediation of NGOs}

- Non-governmental organizations (NGOs) have various roles in social and economic development. One of the most striking has been to serve in the provision of microcredit: as intermediaries between governments, donors, and financiers on the one hand and poor borrowers on the other.

* Recently about 55 million people worldwide, 27 million of them originating from among the poorest - in Asia, Africa, and the Americas - have been microborrowers at any one time, representing probably four to six times as many household members. In Bangladesh alone, there have been around 10 million households with loans outstanding, including among their number perhaps about 30 per cent of all poor households. These figures, combined with the very high rate of growth recorded worldwide of numbers of borrowers from among the poorest.between 1997 and 2001(a 3.5-fold increase), suggests that a target of 100 million borrowers at any one time from this category is not intrinsically unattainable within say the next decade, even if its achievement as hoped by 2005 would demand a huge concentration of effort by governments,

* The modes of operation and outcomes of institutions defined as microcredit lenders have displayed a variety of characteristics, but universal or nearly so have been: (a) the use, as an incentive, of the prospect of further loans for people who have observed repayment obligations; and (b) very low rates of default. Repeated repayments and further borrowing by poor people must mean that the borrowers are generally increasing their material welfare as they assess it, and that they are doing this sustainably through investment.

- Some of the institutions lending to poor people have managed to be fully self-supporting financially, and of these some have been profitable commercial businesses; but those concentrating on the poorest have generally had to rely, at least until very recently, on some subsidy in the provision of capital, and these, including most of the largest microcredit lenders, have been NGOs.

- Nevertheless, some of the biggest NGO microlenders, with a strong concentration on the poor, seem either now to have reached self-supporting status, or to require for it only some possibly attainable combination of higher interest rates, more clients, and a lower scale of overheads.

* It seems likely, however, that start-ups, or rapid expansions, with concentration on the poorest, will continue to need an element of subsidy.

* Yet a degree of subsidization seems in principle perfectly acceptable if it is applied to ventures that provide some of the poorest people with sustainable improvements in material welfare as they themselves judge it - and if there are not more efficient ways of using the resources involved to the same ends.

* So financial self-sufficiency in future transactions may well be an object of aspiration among NGO microlenders, not least because it would give potential access to huge sources of commercial funds that would otherwise be unavailable, but it should not be pursued as an overriding priority and certainly not regarded as a precondition of public sector or charitable support. 
- The NGO microlenders may be regarded on the evidence as catalysts that perform the task of transforming government subsidies, private donations, and commercial finance into opportunities for freely chosen forms of welfare improvement on the part of very poor or poor people, which those people have the opportunity to attain through their own work, creativity, and discipline.

\section{Argument}

\subsection{Resources mobilized by and for} internationally coordinated action

\subsubsection{Why internationally coordinated action may benecessary}

Some global purposes by their nature require coordinated action. Such are some of the vital aspects of economic stabilization, or an international air traffic control system, or the elimination of the infectious diseases that are no respecters of locality. The objectives in these cases can be described unreservedly as global public goods. They entail benefits that must be enjoyed jointly and can not be appropriated exclusively by individual countries. Unless there is coordination among States, there is no way that they can be attained. Some of them require funding, or otherwise entail some form of cost or sacrifice as a condition of their attainment.

But there are other purposes - such as universal primary schooling, or universal access to clean water, or the eradication of diseases that are highly local in their incidence - that embody benefits which could in principle be achieved in and by each affected country unilaterally. But for various reasons, of which a local paucity of resources is prominent, this is unlikely to happen completely and quickly. And a sense of social justice, or solidarity, or compassion - mingled perhaps with very long-term political calculations leads to a widespread view that these are world concerns. We assume that it is right or wise or both - in a world of huge material inequalities between nations - that resources should be to some extent pooled internationally in order to realize everywhere some rudimentary social objectives.

There are cases of objectives and purposes intermediate between this last category and those of the straight global public goods (exemplified by the elimination of certain tropical diseases or of regionally distributed environmental damage) in which the cooperation of several adjacent states may be enough in principle to meet the objective but again its attainment is a global concern that is found in existing conditions to require some global mobilization of resources.

And, as is evident in any setting from a village upward, pooling resources to achieve a common goal requires coordination: the establishment of a fund or say a tally of labour services - to which individuals contribute voluntarily as they see fit, or voluntarily but according to an agreed schedule, or under a degree of sanctioned conditionality or coercion - and institutions for applying the fund or the labour to the agreed purpose. Large common objectives, such as those that the world has officially adopted in the Millennium 
Development Goals, demanding extensive resources, are unlikely to be achieved by random individual action, for example the modest supplements to domestic provision offered by the unilateral efforts of various OECD countries in their ODA. Contributions, however voluntary, by individuals or governments, are far more likely to be adequate if the donors can see the relationship between what they give and what others give, and hence also potentially the link from their own sacrifices to the prospects of fulfilling the big common purposes.

So, whether or not the particular world objectives are properly defined as global publicgoods, a degree of coordinated global funding is likely to be conducive, if not necessary, to their achievement. This will involve funds collected together globally and dispensed under some common direction.

Such global funds should generally not be seen as there to do the job, but rather to fill the gaps, and to endow an entity possessing global credentials with the wherewithal to induce, and encourage, and sustain the (frequently much greater) contribution that must be supplied locally.

For example, the WHO's 2001 Commission on Macroeconomics and Health, chaired by Jeffrey Sachs, assessing possibilities of achieving fundamental health goals by 2015 in low-income, and some middle-income, countries, estimates an annual "funding gap" unlikely to be met domestically and therefore having to be provided from outside - (in 2002 US\$) of US\$22.1 billion in 2007 and US\$30.7 billion in 2015. Filling this gap is seen as necessary - added to the domestic resource-mobilization that it is reasonable to expect for achieving a targeted US\$162.8 billion of total health spending within these countries in 2007 and US\$200.3 billion in 2015. Except in the least developed countries, the great bulk of the resources - and, even in the least developed countries overall, nearly half - are projected as provided domestically. ${ }^{1}$ The project implies a stretching, rather than a slackening, of domestic effort.

\subsubsection{Why not rely simply on an equitable system of governmental contributions?}

The obvious, neat, and rational way of meeting such needs for global funds would be by a system of governmental contributions assessed consensually on some equitable principle. This would be analogous to a domestic system of taxation based on income or wealth. There are of course agreed systems of contributions from member countries along these lines to the United Nations and the specialized agencies and of capital subscriptions to the International Monetary Fund (IMF) and the World Bank group. But there are often big defaults in the UN contributions, with blocks and delays as part of the play of domestic politics. The prospect of a further substantial, regular, agreed schedule of contributions either to the UN and existing multilateral system or to some other ad hoc - international entity or entities - is not generally considered favourable. The recent attempt of the UN Secretary-General to attract annual commitments (spontaneous in the sense of not being part of an agreed schedule) to a Global Fund for Fighting AIDS, Tuberculosis, and Malaria (GFATM), on a scale of US\$7-10 billion a year, has so far shown prospects of reaching only about US\$2 billion a year.

\footnotetext{
${ }^{1}$ WHO, 2001, pp. 166-75.
} 
This does not mean that "the world" is unwilling to provide the funds. It means that individual national governments have taken uncoordinated decisions to provide funds that initially happen to add to US\$2 billion. No one has made a decision not to provide US\$10 billion. It is rather that the world does not have the right machinery - the machinery for making and implementing a decision on its behalf - about the total that will be provided. This is a version of the familiar public good problem. At the least, coordinating institutions are needed to implement a common purpose.

In the world as it is, these institutions must be consensual. Accordingly, the revenue devices set out below are not put forward as means of obtaining funds without the consent of the governments. Governments, or the great bulk of them, will need either to cooperate actively or at least to consent passively. These devices may be seen rather as ways of lowering the political cost for the consenting governments of having the funds approved and transferred. The various devices will probably each have to stand or fall on their capacity to do this.

\subsubsection{Factors that may reduce the political cost}

Four possibly relevant factors that might cause the political cost to be lower than would be the case with a straight additional appropriation for global purposes, or a new run-of-themill domestic tax or tax increase, are the following.

- The revenue devices or appropriations, and their incidence and local opportunity cost, are not highly visible.

- The political cost and effort of framing tax or appropriation measures and piloting them through the legislature are obviated.

- The collection of the revenue is itself linked to the achievement of some widely desired end, such as a recognized global public good, so that two birds can be killed with one stone.

- Any national cost of delivering the revenue is clearly, perhaps even structurally, tied to a world effort, so that there is little or no risk of having to carry free-riders.

Revenue devices are not likely to be appealing unless they meet one or more of these tests. We can call them the visibility, effort, two-birds, and free-rider tests respectively.

\subsubsection{The prior question:} How the funds will be applied?

Crucial to the approval of any additional revenue will be: (a) the machinery for disposing of the funds so raised; and (b) the purposes to which they will be devoted. These are two large additional questions, which we shall do little more than broach here.

Distrust and suspicion of the UN family in the US, and of the Bretton Woods institutions (BWIs) on the part of government and public opinion in many developing countries, make it virtually inevitable that the disposition of the funds can not be committed to either of these two groups of organizations alone and unreservedly. As with the GFATM, some new arrangement or arrangements will probably have to be negotiated. Both the UN family and 
the BWIs, as technically equipped representatives of the governmental stakeholders, may nevertheless play a part with others in helping to frame the constitution and terms of operation and to appoint the controlling body. As in the case of the GFATM, there might be non-official stakeholders also represented. The process of setting up that fund, though stormy, may perhaps provide either a model or else a lesson on how it could be done better. There might be several such funds (labelled here as "multisectoral global funds" or MGFs) for different purposes, with one master fund to allocate resources between them.

Over the purposes to which global funds might be devoted, there are several dilemmas. There is a possibility of concentrating on highly visible, clearly defined, and headline-grabbing activities, such as the vaccination of children, or the payment of primary teachers. Confining global funding to functions such as these may be appealing to donor governments and their constituencies, but it carries the risk that other, less striking functions will be neglected, and the balance among various activities distorted. Often useful action must be complex and many layered in order to be effective. An example is the attack on AIDS and its effects.

There is also a choice over how much interference and "conditionality" there should be. The donors will expect reasonable assurances that their contributions are not wasted. But any form of conditionality runs the risk of substituting foreign for genuinely domestic values and judgments and of weakening any domestic impulse to set and observe consistent priorities. AIDS again provides an example of the risks of formulaic solutions and undue foreign control. The precise aetiology of the infection varies from country to country as does the pattern of secondary diseases, and campaigns to provide information and alter behaviour need to be thoroughly conditioned to the local culture.

Resolutions of these dilemmas - or compromises - will have to be found. The solutions adopted must no doubt depend on political preferences, but it will be important that recipient as well as donor governments should play a part in their elaboration and that nonofficial people and bodies with experience on the ground should also participate. The MGF model, each fund confined to a defined subject, might favour this form of consultation.

The point here is simply that some broad scheme of management and allocation of funds will have to be agreed as a precondition for any large increase in the amounts available for global purposes.

\subsubsection{Candidates with a case for reducing the political pain of providing extra revenue for global purposes}

Six apparent candidates are considered here. Only the last four have useful immediate prospects, but some of these seem promising.

\section{(a) Arms trade taxes}

The notion of a coordinated tax for global purposes on the international trade in arms has an obvious appeal as a disincentive to a generally undesirable activity. It appears to meet the two-birds test. Yet there are four considerations that between them provide a compelling argument against taking it as a serious possibility. 
First, quite a large proportion of legally exported arms are produced by governments or their agencies, and a very high proportion of arms legally imported are bought by governments. So governments taxing either exports or imports would to a large extent be taxing themselves. If not laying burdens on their own defence budgets or their own enterprises, they would probably be differentially taxing an important domestic industry. Second, almost the whole value of arms exports in a recent period came from the rich countries, together with Russia and China, (and nearly 80 per cent from France, Russia, the United Kingdom, and the United States alone). ${ }^{2}$ At about the same time, about half of imports by value were bought by low-income and middle-income countries, which, apart from China and Russia, are almost all net buyers. ${ }^{3}$ If, as is quite possible, the burden of the tax were to fall largely on the importing countries, a number of poor and middle-income countries could between them be contributing to this source or revenue disproportionately highly in relation to their income. Hence, across countries, the burden could easily be regressive. Third, at a constant rate of tax, the flow of revenue would be unreliable. The average value of arms exports over the years 1991-94 was 61 per cent lower in constant dollar terms than over a similar period seven years earlier. ${ }^{4}$ Fourth, the revenue raised would have been quite modest in many years. Even if all governments had complied, and no compensation had been paid to poor countries adversely affected, and at the same time the trade had not been reduced by the tax, a 10 per cent arms export tax in 1994 would have realized about US\$2 billion; and a 25 per cent tax, US\$5 billion.

\section{To summarize}

- Taxing the legitimate arms trade would largely involve governments in taxing themselves.

- Proportionately to income, the burden of a uniform tax would quite possibly fall most heavily on poorer countries, so that internationally the tax might well be highly regressive in its incidence. Together, this and the previous characteristic probably render it out of the question politically.

- $\quad$ Revenue would be highly unreliable.

- On the most favourable assumptions, it would be a modest revenue-earner by the standards of interest here: around US\$5 billion in a recent year from a 25 per cent tax, on the supposition of no compensation to low-income losers and zero price elasticity of demand.

* The tax would not satisfy the invisibility test or the free-rider test. It would go some way to meeting the effort test - insofar as it could be collected if either all exporting countries or all importing countries imposed it. It would arguably meet the two-birds test, though the effect might be rather to burden the budgets of a number of poor countries than to decrease their arms purchases.

\footnotetext{
${ }^{2} \mathrm{UN}$, World Economic and Social Survey 1997, p. 172.

${ }^{3}$ Anthony et al.., 1998.

${ }^{4}$ United Nations, World Economic and Social Survey 1997, pp. 170, 172.
} 


\section{(b) Taxes on the resource rents of deep-ocean minerals}

Imposing charges on deep-ocean mining outside 200-nautical mile limits seems the most promising form of taxing "the global commons". Mining is prohibited in Antarctica. Deepocean fishing might be difficult to tax. Perhaps the most promising alternative in this category would be a fee determined by auction for using radio frequencies. Properly devised, a fiscal regime to which all those obtaining exploitation rights would be subject could be nearly "neutral"; that is, it would have little or no undesirable allocative effects. Moreover, there is actually a treaty providing for an international authority that would administer the resources and impose a charge on those exploiting them. This is the 1982 United Nations Convention on the International Law of the Sea, principally in its Annex III. ${ }^{5}$

So this device passes the visibility, effort, and free-rider tests, and in a real sense governments have already agreed to its use. But so far there has been no mining that would fall under these provisions, and none seems to be in prospect.

\section{To summarize}

- $\quad$ Taxing the resource rents of deep-ocean minerals for global purposes is exemplary on grounds of equity and could be done in a manner that was economically efficient.

- Moreover, its use for global purposes has been agreed, and a skeleton institutional structure has been created for doing it.

- $\quad$ The device would be virtually free of political pain. It would meet all the tests.

- But the activity to be taxed does not yet exist.

\section{(c) Taxes on international air transport}

International air traffic has been rising reasonably fast in most years. Estimates of expenditure on travel for the world as a whole increased in constant-dollar terms by 7.4 per cent a year on average between 1980 and 1990, and by 6.1 per cent a year between 1990 and 1995. ${ }^{6}$ A series for "fare receipts" from international travel increased in constant dollar terms by 4.1 per cent a year between 1992 and $1996 .^{7}$

Air transport may be argued to entail environmental costs (especially "greenhouse" contributions and noise) for which the users often do not fully have to pay, especially since aviation fuel (unlike the fuel used in land and sea transport in many countries) has been exempted from excise duty under the Chicago Convention of $1944 .^{8}$

So an international air transport tax might be a buoyant source of revenue, with an environmental case to be made for it - though there is no obvious reason to think that international flights have any greater costs than domestic ones per passenger- or freight-

\footnotetext{
${ }^{5}$ Bernaerts, 1988, pp. 58, 84, 121-2, 272-8.

${ }^{6} \mathrm{UN}, 1997$, p.184, with figures deflated by US export price index.

${ }^{7}$ World Tourism Organization, 1998, vol. 1, p. 9.

${ }^{8}$ International Civil Aviation Organization, 2001.
} 
mile or per fare- or tariff-unit. It could be easily and reliably collected. In its impact on users, the burden of the tax would be equitably enough distributed, tending to bear more highly on richer people and on richer countries, and quite possibly on the whole progressively.

But its effects on the suppliers of tourist services could raise awkward questions of equity. It is the tourist-passenger market that is likely to be sensitive to changes in fares. And it happens that a number of small middle-income countries are highly dependent on tourism for their income. (According to The Economist, ${ }^{9} 44$ per cent of the GDP of Antigua and Barbuda, 39 per cent that of Saint Lucia, and 54 per cent that of Guyana, arise from tourism. Guyana in 2000 just scraped in at the bottom of the World Bank's low-middleincome category.) Unless the tax is set at a very low rate or on freight only, these countries might well be aggrieved and require at least compensation, and it might be difficult to make compensation really adequate if the tax substantially damaged such a staple industry.

Moreover the use of this device would do little if anything to reduce the political pain of additional taxation. It will be simply another tax, quite visible, that must go through the ordinary legislative process in each country, and that each country might well have imposed independently for its own purposes if it had been so minded. The reduction of international air traffic is not a particularly popular cause except among those who live around airports without living from them. So the two-bird test is the only one of the four that might be met, and that dubiously. Governments that applied a tax to air transport would probably need some additional good reason for not using the proceeds themselves.

By the standards considered later in this section, revenue would not be huge, but it could be far from negligible at rates of tax that might be contemplated. A rough estimate of the receipts from a tax on passenger fares alone, assuming unit elasticity of response of demand to the price, would suggest for 1996 that a 10 per cent tax would have yielded about US $\$ 5$ billion, and a 25 per cent tax about US $\$ 11$ billion. ${ }^{10}$ A more authoritative estimate $^{11}$ gives the revenue from a 1 per cent tax on all international passenger tickets and freight transport as US $\$ 2.2$ billion a year, and, on passenger tickets only, US\$0.8 billion. These two sets of estimates are not wildly inconsistent with one another - the second, however, somewhat more optimistic over revenue possibilities from a passenger fare tax than the first. It would imply that, with unit price elasticity, a 10 per cent tax on both freight and passenger fares would yield nearly US\$20 billion, on freight alone about US $\$ 12$ billion, and on passenger fares alone between US\$7 and 8 billion.

\section{To summarize}

- An international air-transport tax could be easily and reliably collected.

- It would provide a buoyant source of revenue over the longer term.

- An environmental case can be made for it, though the case could be made more convincingly for a tax on all air transport.

\footnotetext{
${ }^{9} 23$ Nov. 2002, p. 59.

${ }^{10}$ Based on the World Tourism Organization, 1998, vol. 1, p. 9, with the figure given there for "fare receipts" reduced by 20 per cent to account for journeys other than by air.

${ }^{11}$ Commission for Sustainable Development, 1995, p. 27.
} 
- The burden of the tax on users would on the whole be progressively distributed, both internally and internationally.

- But the burden on suppliers would bear particularly hard on countries specializing as tourist destinations, which are often poor with few alternative exploitable resources and might need compensation.

* Of the criteria for reducing political pain, it could meet only the two-bird test, and that uneasily.

- Without any allowance for compensation, and with complete coverage and the highest rates likely to be tolerated, revenue is unlikely to be above US\$20 billion.

\section{(d) A tax on carbon-use or equivalent}

The burning of hydrocarbon fuels, with consequent production of carbon dioxide, is believed now to be the largest of the anthropogenic elements in global warming. The various fuels contribute in proportion to their carbon content. A uniform tax on their use in proportion to the amount of carbon burned would appear to be an efficient disincentive, incorporating consistently an element of the external cost into the price facing users. Even more efficient would be the extension of the tax to emissions of other greenhouse gases or even to other changes too, such as deforestation - in such a way that acts entailing equivalent contributions to global warming would be equally taxed. Appropriate conversion factors are internationally recognized: for example, to check compliance with fulfilment of commitments under the Kyoto Protocol. They allow not only hydrocarbon fuels but also other sources of emission, and even changes of land use, to be expressed in carbon-equivalent units. But we shall consider the tax here as if it were to be applied to the use of commercial hydrocarbon fuels only.

So a carbon tax devoted to globally available revenue has the additional attraction that it would be a contributor to meeting a major global environmental challenge. Apparently the two-bird test would be met.

The tax would also be relatively cheap and easy to impose and enforce. It could be collected on the wholesale or retail sale of each fuel at a specific rate determined by carbon content. Such excise taxes on uniform, bulky commodities, some of them entering the market in any country from a limited number of sources (or imported), are among the easiest to collect in a watertight fashion. Often the administrative arrangements for collecting excises on fuels are already in place.

For 1996, the World Bank ${ }^{12}$ gives a world figure for carbon-dioxide emissions that reduces to 6.18 billion metric tons of carbon, roughly a metric ton per person. A uniform carbon tax amounting on motor gasoline to US\$2 per US barrel, that is 4.8 cents per US gallon, would represent US $\$ 17$ per metric ton of gasoline, which, at an approximate carbon content of 0.81 , would mean roughly US\$21 per metric ton of carbon. These figures imply world revenue for 1996 of US\$130 billion (roughly 2.5 times the typical level of ODA in recent years) if use of hydrocarbons was unaffected. High-income countries alone, on the same basis, would raise US\$61 billion.

${ }^{12}$ World Development Report 1999/2000, p. 249. 
The difficulty of introducing the tax, in its ideal form as a uniform worldwide measure, is not technical but political. Every one of 200 or so governments would have to legislate for it and administer it. At best, we could probably expect its application to be gradual and patchy, with exemptions in many countries for politically sensitive uses. But universality would not be essential, especially for a tax at the very low rate suggested, for which questions of international competitiveness would hardly enter into.

To induce every government in the world to collect a uniform carbon tax and direct the proceeds internationally would indeed be an extraordinary achievement. But it is not out of the question that the tax should be imposed by the high-income countries alone, or at least that they alone should covenant to surrender the proceeds for global purposes. Some countries - notably the Scandinavians and Slovenia - have already applied carbon taxes that are more or less comprehensive in concept - though always with some exceptions and at much higher rates than the one just mentioned. ${ }^{13}$

But it is a complication that most countries already impose duties or subsidies or both on various forms of hydrocarbon use. It might not be morally, legally, or politically workable to insist that the prescribed rate of duty should be additive to what already existed. Should those countries already collecting semi-comprehensive carbon taxes at much higher rates be obliged to keep these rates and add this genuinely uniform increment? What if instead they chose to impose a similar additional fiscal burden in total on hydrocarbons but at the same time to make the overall rates on carbon more nearly uniform? Particular fuels kerosene for lighting and cooking in some places, motor fuel in others - may be especially sensitive politically. For revenue purposes it would be enough if the various governments agreed with each other to devote to international uses the equivalent of what would be raised by a tax of $x$ US dollars per metric ton of carbon. To formulate the obligation this way would be to abandon much of the environmental rationale - though it could be argued that the governments, by agreeing to this rule, would be giving themselves a fiscal incentive for measures discouraging carbon use.

Despite that rationale, the device would begin to look more like an international tax assessed on various nations' governments - and according to a criterion that had only a very weak relationship with ability to pay. Abandon all but the shreds of the environmental rationale, and the question naturally arises whether this is a fair way of levying nations for global purposes. Taxing in proportion to carbon use would be very different from taxing in proportion to income. At any given level of income per head, nations' use of carbon per head varies considerably. And, most awkwardly, some poor countries have considerably higher use of carbon per unit income than some rich countries. On the carbon dioxide emissions (1996) figures and GNP (1998) figures given in the World Development Report 1999/2000, India's carbon use per unit GNP, on exchange rate comparisons, was 3.5 times as great as that of the USA, and China's on the same basis 12.5 times as great as Japan's. On a PPP (purchasing power parity) comparison, India's rate comes out slightly lower than the United States', but China's is still 2.2 times that of Japan and 1.25 times that of the United States. There could be arguments over which of these methods of comparison is more relevant to this issue. But even the more favourable of them would make this tax still highly "regressive" (its average rate on income inversely related to the level of per capita income) between the poor country with the world's largest population and the rich country with its second largest economy.

13 The rates on motor gasoline in Sweden and Norway in the late 1990s were about eight and nine times respectively the rate suggested here if $1 €$ is taken as equivalent to US\$1; and of course many countries have total tax burdens on motor fuel that are similarly immensely higher than 5 US cents per US gallon. 
This consideration, if no other, leads to the suggestion that, even if the tax were actually imposed across the world as an (additional) charge impinging on every user of commercial hydrocarbon fuels, only the high-income countries' governments should accept the obligation to devote the revenue to global purposes. The rest would keep the proceeds themselves. This, on the very modest rate of tax suggested above, would still (ideally) leave the annual internationally available revenue a little higher than the typical annual value of ODA.

A further political obstacle in the way of a universal carbon tax is that the governments of countries that were net exporters of hydrocarbon fuels, especially of those heavily dependent on this trade for their incomes, would be against it. However, the refusal of the countries highly specialized as oil producers to cooperate would not in itself greatly diminish the revenue.

Perhaps the critical weakness of the practical case for a carbon tax directed to global purposes - even for one confined to the rich OECD countries - is similar to that applying to the air transport tax. It meets only one of the four criteria for reducing political pain, the two-bird test, and that awkwardly. If the tax is not really additive to what already exists, the environmental case for it is weak. Even if additive, the small rates of duty that might pass as politically innocuous would probably do little to reduce the use of hydrocarbons. And most countries increasing fuel duty would naturally look to keep the proceeds.

The use of hydrocarbon fuels has risen considerably over the past 50 years, though not quite consistently - with a downturn from 1979 to 1982, when energy costs were unusually high and economic activity went into recession. At most times, however, it has continued on a markedly rising trend in spite of big fluctuations in fuel prices. The small additional levy mooted above, if it were genuinely additional, could be expected, at most, and after a delay, to lower the growth path, and possibly the trend rate of growth, slightly. Failing much more drastic measures or big technical developments, hydrocarbon use could not be expected actually to fall. In fact, because the tax at the rates suggested would be so weak as a measure against global warming, it would very probably (for say the next decade, possibly much longer) be a rising source of revenue. Doubling the rate suggested - which would still entail a fairly small rise in fuel prices in relation to recent market fluctuations would also seem very unlikely in itself to have much immediate effect on use, or turn a rising trend into a falling one.

\section{To summarize}

- A uniform carbon tax would be cheap and easy for national governments to impose and collect, but, if it were to be a genuinely universal additional charge impinging on every user of hydrocarbon fuels, the 200 odd governments of the world would need to cooperate in legislating for it and administering it.

- Its allocative effect would be favourable, tending if anything to compensate for one of the major global environmental externalities now causing concern - and all the more so if (not impossibly) it were to be combined with equivalent taxes on other greenhouse activities.

- A possible variant is that the governments should simply commit themselves to deliver internationally the equivalent of the proceeds of a carbon or carbon-equivalent tax of so much per unit, though this would remove much of the tax's attraction on environmental grounds. 
- Suppose over the relevant range an elasticity of demand close to zero; then at rates of tax that would be small in relation to the price changes frequently experienced in the market - rates that would be little noticed by final consumers in rich countries - a carbon tax universally enforced could raise revenue for global purposes amounting to roughly 2.5 times current ODA; one on high-income countries alone, perhaps 1.2 times.

- $\quad$ Failing other much more drastic changes, taxation at these rates would at most lower the path, and perhaps reduce somewhat the trend rate, of increase of hydrocarbon use; so that revenue in most years would still rise.

- However, across countries the burden of the tax would be far from proportional to income. Some poor countries would be delivering in revenue a higher, occasionally a much higher, proportion of income than some of the rich.

- Also, the countries specializing in hydrocarbon production, while they might not suffer seriously as a result of the rates of tax suggested, might well be opposed.

- On both grounds there might well be political obstacles to the universal application of the tax.

- However, if even the high-income countries alone (excluding the handful of small oil specialists among their number) imposed the tax at the very low rate contemplated and delivered the proceeds internationally, funds resulting would exceed current ODA. And imposition by high-income countries at say twice these rates, with still probably little immediate erosion of the tax-base as a result, would not be out of the question.

- But, of the four criteria of political pain reduction, this device would meet only the two-bird test, and the case for it on that ground in practice would probably rate as thin.

\section{(e) A currency transaction tax (CTT)}

The idea of a worldwide tax for global purposes on all exchanges of currencies had by the mid-1990s developed considerable interest because of the huge volume of the transactions that would be targeted, the correspondingly minute tax rates apparently needed to generate substantial revenue, and the possibility that such a tax might simultaneously have some function in stabilizing exchange rates. At the same time the notion seemed capable of generating passionate hostility.

A record of the reasoned debate and analysis on the topic as it had progressed to that time is provided by Ul-Haq et al., eds., 1996. The device that was taken to be under discussion in that symposium was a uniform tax on all currency transactions at a very low rate, probably of the order of 0.1 per cent or less, imposed and collected, in the markets in which the exchange contracts were made, by the respective governments within whose jurisdictions the markets took place. The case in favour generally supposed that the tax would be used for both revenue and stabilization purposes.

There were briefly two sorts of difficulty or doubt about the device so conceived. 
One, on policy, was that of using the same instrument for two quite different purposes. If the tax could prove useful for stabilization, it would seem likely that this would be the case only over a certain range of values. There was no clarity on what this range was or that values within this range would be productive of abundant revenue. If, on the other hand, a rate was fixed that seemed optimal for revenue purposes, there seemed to be no guarantee that it would be valuable, rather than the reverse, for stabilization.

The second set of doubts concerned implementation. It seemed that exchange contracts need not be made in established markets or even at identifiable sites. If so, it might be difficult for any authority reliably to tax them. Even if this difficulty could be overcome, there might be fatal gaps in enforcement unless every country's tax authority was willing and able to cooperate. It might be easy for markets to move from sites where they were taxed to any in which they were not.

These difficulties were not necessarily conclusive against the tax. There might be satisfactory compromises between rates ideal for revenue and those ideal for stabilization. There would be risks and other costs for transactors of exchanging currencies outside established markets, and also costs of relocating the markets; so that rates that were low enough might be capable of implementation if at least the authorities in countries with developed financial markets agreed to apply the tax. But the case remained an uneasy one.

Since then, however, these doubts have been largely resolved by two developments of the later 1990s.

First, Spahn ${ }^{14}$ suggested how the policy dilemma might be resolved by the simple expedient of having a multi-tier CTT: making the tax effectively into two or more independent instruments. There might be a CTT at a very low rate applied permanently and universally for revenue. And there might also be a CTT, possibly at a much higher rate, applied only when and where it was needed for specific tasks of stabilization. Such fiscal methods, Spahn argued, ${ }^{15}$ would in general be more efficient - less costly in a number of ways - than administrative or monetary methods if a government at any time considered it necessary to moderate capital flows. As an example he proposed the use, by individual countries that might be at risk of self-fulfilling currency flights, of a CTT at a high rate announced as held in reserve to be applied automatically to outward exchange transactions if the rate of fall of the exchange rate should exceed a certain threshold. This could serve as a form of circuit-breaker.

We are not here concerned to discuss the possible stabilization uses of the CTT, but, in order to clear the air, we shall say that we are not supposing any stabilization function for a universal CTT at a very low rate such as might be applied to raise revenue. That proposed use of the tax, originally mooted by James Tobin, we shall ignore, as overtaken by more promising ways of employing a CTT to steady exchange rates, ways that need not impinge on its use for revenue.

\footnotetext{
141996.

152002.
} 
Secondly, Schmidt ${ }^{16}$ provided what seems to be an answer to the implementation difficulty. He showed how the institutions under which national banking systems settled foreign exchange transactions in the transactors' accounts had reached a point at which the monetary authorities of most countries with sophisticated banking systems - including many developing countries - could readily identify and tax gross (wholesale) transactions into and out of their currencies. They could do this through a combination of their authority over their own foreign exchange banks and their bargaining power over offshore netting systems. This had become possible because of the arrangements, increasingly internationalized, that had been adopted in order to protect transactors against settlement risk. In fact the monetary authorities already levied bank settlements of currency transactions in order to pay for use of the information software needed to sustain the systems of simultaneous settlement.

This meant that a CTT would not have to rely for its implementation on the taxing of currency markets - which were largely unregulated, dispersed, and possibly footloose and could instead be assessed and collected through the process of settlement, which was regulated and centralized and must take place ultimately in the banking systems of the two currencies involved in any exchange, supplemented by offshore netting systems that would need to be given access to the relevant banking systems. Transactions entailing the exchange of securities rather than cash could be dealt with by similar means because securities are exchanged on large centralized exchanges that are supported by integrated securities payment systems. Apart perhaps from certain elements of exchanges taking place through derivatives, implementation would be simple, watertight, and extremely cheap. This would be the case so long as at least one of the banking systems associated with the two currencies involved in an exchange had a "modern, large-scale settlement system". Since virtually every wholesale transaction involves at least one of the five "vehicle currencies" - all of which meet this condition - virtually all wholesale transactions involving cash could be readily covered. There would also be plausible ways of dealing with derivatives, though, as with income tax, the enforcing authorities might have to be on the lookout for ingenious devices aimed at avoidance or evasion. (Interestingly, George Soros ${ }^{17}$ - although, assuming as he did in early 2002 that all currency markets would have to be taxed, he was dubious about whether sufficient participation could be mobilized for a CTT to be effectively applied - believed, doubtless on the basis of practical experience, that otherwise the problem of taxing exchanges taking place through derivatives could be easily solved.)

The same analysis implied that a number of countries - including many of those that might fear currency crises - could apply a CTT on exchanges into or out of their respective currencies unilaterally, and thus, at their own discretion, use the device to ration or delay inward or outward capital movements for reasons of stabilization. Thus what Spahn had suggested as a way of impeding sudden currency flights would be readily available to a number of countries without the need for international agreement. It might also be used to ration short-term capital inflows or long-term capital outflows if any government chose to do either of these things, and the method would be prima-facie more efficient and transparent than the use of administrative controls. And any such unilateral use for stabilization could be completely independent of the international use of a CTT for revenue.

\footnotetext{
${ }^{16} 1999,2001$.

${ }^{17} 2002$, pp. 71-2.
} 
The analysis also appeared to mean that, between them, the authorities issuing the five vehicle currencies - the dollar, euro, yen, pound, and Swiss franc - could, if they cooperated, tax virtually all transactions, since in virtually all of them one or other of those currencies would be involved on at least one side. It would, however, be a useful precaution if the authorities of a few - perhaps eight - other currencies that might come to be used as vehicles were prepared to cooperate in applying the tax if the need should arise.

So it would seem that the active participation of five authorities, with a few others agreeing to act if needed, would suffice to enforce a universal CTT for revenue purposes.

It is generally taken that the allocative effect of the tax - its effect in deterring "real" international transactions through raising the cost of currency exchange - would be negligible at the very low rates of tax generally discussed. Even if a 0.1 per cent tax added several times its amount, say 0.5 per cent, to the cost of the transaction, this, though a burden, would seem unlikely to have much effect on trade or long-term investment.

The rate of tax, however, would be a sensitive question for two reasons, each depending on the fact that little is known about the responsiveness of the volume of transactions to any levy. A rate that was high enough to reduce the volume considerably might significantly increase the cost of "real" international transactions such as trade and long-term investment - or so it might be argued. It is also quite likely that increasing the rate above a certain critical level would actually reduce the revenue take.

For these reasons it seems sensible that the tax should first be introduced at an extremely low rate, which might then be raised by small increments in order to judge the effect on the market and hence on the amount of revenue. Spahn ${ }^{18}$ suggests 0.02 per cent, and gives reasons for thinking that a rate of that order would have little or no effect on the volume of transactions. Total global currency transactions, as reported in daily form by the Bank for International Settlements (BIS), were of the annual order of US\$360 trillion for 1998 and US\$264 trillion for 2000, on the assumption of a 240 -day trading year. ${ }^{19}$ If the 0.02 per cent rate of tax had in fact no effect on the base, it would raise, on the year 2000 figure, US\$53 billion, roughly the amount of ODA. But this should probably be thought of as a minimum rate that might well turn out to be capable of being raised substantially, with a resulting increase of revenue and without any disastrous outcome for trade or long-term investment. Recent estimates made by Felix, ${ }^{20}$ on assumptions about evasion and exemptions and two different assumptions about the buy-sell spread in the market, are that a 0.25 per cent tax might raise US $\$ 260$ billion, and a 0.1 per cent tax US $\$ 186$ billion. These figures, however, depend on supposing that the annual volume of transactions would be US $\$ 400$ billion. On a base of US\$264 billion, derived from the latest BIS figure for the latest year, these figures would presumably shrink to US\$172 billion and US\$123 billion respectively.

This downward revision draws attention to two awkward elements. One is that the BIS figures for the aggregate of transactions do not appear to be very reliable. The value quoted for 1998 in the 1999 publication was revised downward by nearly 25 per cent in the next edition two years later, and some figures originally given for earlier years were similarly

\footnotetext{
${ }^{18} 2002$.

${ }^{19}$ BIS, 2001, p. 98.

${ }^{20} 2001$.
} 
drastically reduced. ${ }^{21}$ The second is that, if we believe the figures in the 2001 publication, the total had actually fallen in nominal terms by 27 per cent between 1998 and 2000, much further than could be directly attributed to the introduction of the euro in 1999. Though the aggregate had for some time risen consistently, or even explosively, until 1998 (the annual rate of growth recorded by the BIS from 1989 to 1998 amounting in nominal dollar terms to 11 per cent, ${ }^{22}$ this recorded fall suggests that the actual revenue at any particular rate may not be highly consistent from year to year.

Though of course a CTT in the form mooted here would entail a burden, the burden would, with one important exception, be highly diffused. It would not impinge obviously in any severe way on any particular nation and probably on only one occupational or industrial class. Politically that would be an advantage. But the one class of people who would often be detectably hit by the tax would be a vocal and influential one: those engaged in financial dealing and financial services. Politicians have become used to trembling over the opinions of "the financial markets". The opposition of those engaged in finance will not easily be ignored.

Aside from the element of the tax burden that will fall on this sector, it seems likely to be distributed across countries more or less in proportion to their absolute involvement in "real" international transactions (trade, remittances and other transfers, long-term investment). This part of the burden will tend to bear a very rough proportionality to income, but, at any average income level, there will be variation in "openness" among economies, and this will be reflected in variation over their share of the tax burden. So it will not be consistently "proportional" in the way the burden is distributed in relation to income. However, any tendencies to "regressiveness" seem unlikely to be nearly as great as in the case of a uniform carbon tax. The other element of the burden - that falling on the finance industry - will be concentrated in richer countries, and this will tend to add a "progressive" element, as well as having a populist appeal. And any inequities will be much less obvious than in the case of a carbon tax: discerned if at all by reasonable guesses rather than blatantly revealed by hard figures. This characteristic will surely be important to the comparative acceptability of the two taxes. Apart from its impact on the financial sector, the CTT does well on the invisibility test.

The fact that cooperation on the part of five monetary authorities, with at most a few more in reserve, will suffice to implement the tax has several implications.

First, there is an overwhelming moral case for the view that, if the tax is applied at all in this way, the revenue should be internationally employed and not left at the disposal of the country that raises it. Since the burden would be widely spread, it would be rightly regarded as scandalous if a few rich countries appropriated the revenue, or any significant share of it, for themselves. This particular form of tax could thus be said to have a comparative advantage for international use, as well as requiring international cooperation for its implementation.

\footnotetext{
${ }^{21}$ BIS, 1999, p.117; 2001, p. 98.

${ }^{22}$ BIS, 2001, p. 98.
} 
Secondly, the fact that five authorities would suffice for implementation is on the face of it an extraordinary advantage for the tax's practicality over most possible taxes whose imposition would need to be coordinated internationally. Nevertheless the opposition to it that has been worked up in the United States, especially in the US Congress, is awkward given that United States cooperation is crucial.

Third, however, this system of implementation would give each member of the five - but most obviously of all the United States, which would have by far the biggest capacity for raising the revenue - a very effective veto over deployment of the proceeds. ${ }^{23}$ Each of the five individually could make the implementation of the tax unworkable - since withdrawal from cooperation on the part of any one would almost certainly make continued participation unacceptable to all the others. Yet politically this fact, starkly obvious in the system of implementation envisaged here, could be an advantage. Congressional opposition in the mid-1990s to the use of the CTT was embodied in the phrase "taxing US citizens without their consent". ${ }^{24}$ Yet in the system envisaged it would be the US that would be doing the lion's share of the taxing, and, if any authorities could be described as taxing the citizens of other countries without their consent, it would be those of the United States and the other members of the Big Five. ${ }^{25}$ The simple practical point is that the United States would have to approve the way in which the revenue was used. The system adopted for disposing of the revenue, and the guidelines for its allocation, would of course need to have the approval of the United States in advance. But, if there were any fear that those constitutional arrangements might provide insufficient protection, there would be the daily sanction of being able to pull the plug. If at any time "US citizens" as a body were held by their representatives not to be satisfied, a veto could effectively be applied and the system would collapse. If this incontrovertible point could be emphasized, it might at least mitigate the opposition.

Hence, if opposition in the United States can be regarded as a contingent phenomenon, rather than a matter of settled objective interest, the device would go far towards satisfying the effort and free-rider tests.

\section{To summarize}

- The tax would be imposed on a base that is so far largely unexploited for revenue purposes.

- $\quad$ Collection by the method suggested here - on bank settlement of transactions - would be cheap and could readily be made watertight.

- Universal application would require the active cooperation of only five authorities, though it would be a useful precaution for perhaps eight others to agree to take part if need should arise.

\footnotetext{
${ }^{23}$ Under the system of implementation envisaged here, each monetary authority - subject only to arrangements for avoiding double taxation of the same transaction - would tax transactions involving its own currency, and the US dollar is the most heavily traded by far.

${ }^{24}$ Every country, needless to say, does tax citizens of other countries without their consent through taxes on international transactions such as imports - and the CTT is another form of tax on international transactions.

${ }^{25}$ Of course, it would be highly desirable, if not necessary, that there should be unanimous, or at least very wide, international support for the operation.
} 
- So, for the rest of the world, it would satisfy the effort test, and, because of the small number of active participants needed, it would go far towards satisfying the free-rider test.

- Though there has in the past been intense and emotional opposition to the tax in some influential United States circles, the fact that the system of collection suggested here would give the United States effectively a day-to-day veto over the means of disposal of the revenue might be used to mitigate this opposition in so far as it had a rational element.

- The revenue from this tax - however collected, but most obviously with the method suggested here - would in a moral/political sense have a special comparative advantage for international use, since the burden would be widely spread across both rich and poor countries, whereas those that would be collecting it would be rich countries, and, even among these countries themselves, the revenue collected would bear little or no relationship to the burden borne. So its retention by the governments that collected it would be highly objectionable.

- It is generally taken that any adverse allocative effects of the tax at the rates usually discussed - generally 0.1 per cent or less, or at most 0.25 per cent - would be negligible. Even if the increase in transaction costs on such "real" international dealing as trade, remittances, and long-term investment amounted to say 4 or 5 times the rate of the tax itself, the impact would not be great.26

- The burden of the tax could be seen as having two main elements. Its distribution between the two would be hard to guess and would depend, among other elements, on rates of tax and how far the volume of transactions responded to them. One part could be expected to fall on the finance industry - because, even though the tax would be "passed on", any reduction in volume of transactions would tend to reduce the earnings in this sector. This part of the burden would be concentrated in rich countries. The other part would fall on the populations of all countries in rough proportion to their engagement in "real" international (or at least inter-currency area) transactions (trade, transfers/remittances, and long-term investment). This latter part would be only roughly proportional to income, with the more 'open' economies at any income level tending to bear a larger share. But, given the concentration of the finance-industry part of the burden in rich countries, the burden would probably tend overall to be progressive in relation to income across countries.

- It would be a political advantage that the burden, apart from that part falling on the finance industry, would be diffuse and not readily identified. So, for a huge majority of people in every country, the device would meet the invisibility test. But the probable opposition of those within the finance industry, who as a group are influential, would be an obstacle.

- Because we have no clear idea of the reaction of the currency markets to the tax, and hence also no clear idea of what rate of tax would generate most revenue, or above what rate the addition to transaction costs in trade, remittances, or investment would come to have a significant effect on those "real" transactions, it would be best to apply the tax experimentally at a very low rate, and then to raise it by small increments - in order to record the effects on the volume and total cost of transactions while simultaneously studying the markets in order to explain whatever changes were observed. Trial and error, combined with increasing understanding, might eventually allow a point to be reached at which an informed judgment could be made over desirable rates.

${ }^{26}$ It seemed best here to ignore the question whether such very low revenue rates of CTT, applied universally - as distinct from ad hoc uses of a CTT for stabilization purposes - would have a favourable or an adverse effect on the stability of exchange rates. 
- It has been suggested, on the basis of some analysis of the currency market institutions, that a rate of 0.02 per cent would have very little impact on the volume of transactions. This might be a good experimental starting rate. If it in fact had no impact on volume, it could be expected to raise about US\$53 billion on the volume estimated for the year 2000. This would be roughly equal to annual ODA. Other informed guesses made recently about responses would, if applied to the year 2000 aggregate, give US\$172 billion for a 0.25 per cent tax and US\$123 billion for a 0.1 per cent tax, respectively about 3.5 times and 2.5 times ODA.

* Revenue at any given rate might not be very reliable from year to year. Though the aggregate of transactions, as recorded in the latest estimates, had risen unremittingly until 1998, it appeared to fall by about 27 per cent between then and 2000 .

\section{(f) Creation of Special Drawing Rights (SDRs)}

The attraction of SDR creation as a source of globally available funds may be seen in several ways. First, SDRs constitute an asset that exists only because of its creation by an international institution; they are a by-product of the quest for a particular global public good: economic stability and full employment of resources. It might seem natural to regard them as belonging to the world as a whole. Second, in certain circumstances, namely when the creation of SDRs enables world output to be higher than it would otherwise be, it is quite possible that the combined operation of creating them and dedicating some of them as funds for global purposes will serve to generate those funds at no overall net cost: in other words, the rise in world output and income that results may equal or exceed the value of the funds so dedicated. Third, even when that is not clearly the case, still, because:

- the SDRs come to national monetary authorities without payment;

- their uses are still somewhat restricted with a view to enhancing their reserve function;

- a number of the authorities have more than adequate reserves (or could, if they needed, obtain more at similar cost), arrangements for certain countries to give them up for global causes can probably be devised that are likely to impose minimal overt sacrifices on the countries forgoing them.

There are two questions: first, whether the use of SDRs for allocating resources to particular global ends can be made consistent with their use in stabilization; and second, if so, what are the minimal institutional changes needed to make this possible and effective.

Special Drawing Rights (SDRs) were authorized in 1969 as a means of increasing international liquidity, both by allowing quantitative increases in international reserves and by rendering reserves more reliable in value through untying them from particular currencies. The ultimate purpose of the capacity for SDR creation can be described as contributing to economic stabilization at a high level of activity. The idea behind them was that a shortage of internationally-liquid assets available to be held in national reserves might oblige countries to restrict demand, with the result that their output would fall below capacity. Various countries that were in this position or potentially so would aggravate the situation for one another. Extra liquidity, in other words, might at any particular time be needed for the world economy to produce at its full current potential. 
SDRs are issued by the IMF. There have so far been two rounds of creation of SDRs, each spread over three years, the last completed in 1981. Each round must be approved by the Board of Governors of the IMF (in which all member governments are represented) by an 85 per cent majority. Under the weighted voting system, the majority required means that a small number of industrial countries, or indeed the US alone, can veto any new creation. There was insufficient support for new rounds from 1978, when the last was approved, until 1997. Through the 1980s, it was the opposition of Germany, Japan, the United Kingdom, and the United States, that ruled out any further allocations, in spite of the fact that the representatives of almost all the rest of the world were in favour. ${ }^{27}$ SDRs have been distributed to IMF members in proportion to their IMF quotas, and any change in that arrangement would require an amendment to the IMF's Articles of Agreement.

An attempt in 1997 to make a further allocation in different proportions, designed - in a move actrually initiated by the US Administration - to bring the cumulative proportions of SDRs received until that time into line with the various member countries' current quotas, was approved by the IMF's processes, together with the necessary Fourth Amendment to the Articles of Agreement (to allow an allocation other than in proportion to current quotas), but the amendment failed year after year to reach the required level of ratification by 110 members with 85 per cent of voting power. By the end of April 2001, 107 members with 71 per cent of voting power had ratified. ${ }^{28}$ At that time it had yet to be ratified by the US Congress, whose failure to do so is alone enough to prevent it from going forward, so that the allocation has still (late 2002) not been made.

Since 1958, well before SDRs came into being, there have been recurrent suggestions for using the international creation of liquidity as a source of international aid. The idea was by no means ruled out of intergovernmental and high-level discussion. It was endorsed by a vote of the UN General Assembly in 1980 and advocated the same year in the much publicized Report of the Brandt Commission. Through the early and mid-1980s, IMF staff aired a number of possible options and three of the Fund's Executive Directors (from Belgium, France, and India respectively) each put forward a specific proposal. ${ }^{29}$ Recently, the idea that additional funds for development and for helping to fulfil such global objectives as the Millennium Goals could be generated by resuming SDR creation (in particular as a means of reducing the costs to developing countries of the increased holdings of reserves in which many of them had engaged since the 1997-98 East Asian crisis) was floated by the Zedillo Panel in its report to the UN Secretary-General in 2001. ${ }^{30}$ The Panel argued that this would also tend to reduce the demand for US dollar holdings and thus discourage the indefinite increase of the United States short-term debt. Some months later, George Soros put forward, as part of the central proposal of his book, On Globalization, ${ }^{31}$ the idea that there should be regular creations of SDRs and that the rich countries should agree to make their allocations available for global public goods and for aid to development in individual countries. He proposed that the process should be started with the activation of the approved allocation of 1997, under which the rich countries' share, which he envisaged devoting to global purposes, would be US\$18 billion. Under current quotas, the rich countries' share of any subsequent allocation would be 61 per cent.

\footnotetext{
${ }^{27}$ Boughton, 2001, p. 945.

${ }^{28}$ IMF, 2001, p. 67.

${ }^{29}$ Boughton, 2001, pp. 947-9.

${ }^{30} \mathrm{UN}, 2001$, pp. 58-9.

${ }^{31} 2002$, Ch. 2.
} 
Soros' idea has the advantage that, once the allocation of SDRs had been made, the diversion to aid and global purposes would not have to await universal agreement. If some of the rich countries refused to participate, this need not stop the rest from doing so. If the European Union (the ECB and the member countries outside the euro) took part, for example, this alone would provide a significant share of any allocation and might encourage the others.

With qualifications, SDRs can be seen as liquid assets - money - created by the IMF, in somewhat the same way as national monetary authorities issue their currencies as liabilities against themselves, and as commercial banks in their lending operations similarly increase the stock of money by giving short-term liabilities against themselves in exchange for longer term claims on their customers. Institutions with sufficient credibility are in a position to do this. The public is prepared to treat these institutions' short-term liabilities as money. However there are certain peculiarities about the way in which SDRs were created. They were to be issued to IMF members in proportion to those members' IMF quotas ("subscriptions"), but no other asset would have to be surrendered in exchange for them. And originally only central banks or analogous bodies were to deal in them. They "cannot be classified according to such familiar categories as "legal tender", "money", or "credit". They are sui generis", wrote Joseph Gold, the IMF's General Counsel at the time of their creation. ${ }^{32}$ Their characteristics represented a compromise.

It would have been possible to create a form of international money that was like gold, or like currency notes and coins, in the sense that it bore no interest: liquid or semi-liquid assets denominated in it might be obtained through the transfer of other assets to the issuing authority, but simply holding it would earn the holder no income. But holders of SDRs do earn interest on them from the IMF. Against this, however, each country pays interest, at the same rate, to the IMF on its total cumulative allocation. The effect of this is that those holding more than their cumulative allocations of SDRs are net recipients of interest, while those holding less are net payers. ${ }^{33}$ For those who simply hold on to their allocations without increasing or reducing them, their holdings of SDRs resemble a non interest earning reserve, like gold stored under the bed. Once the original recipient transfers them to other authorities in exchange for gold or currencies, however, they become to that recipient more like a loan without a terminal date, on which interest (at short-term rates) has to be paid. The original recipient pays to the IMF the amount of interest that any subsequent holder will receive. Another way of seeing it is that those holdings of SDRs that equal a monetary authority's cumulative allocation are like gold. Any excess is treated as a loan to the system, and any deficiency as a loan from the system.

But, beside these rewards for holding them and penalties for giving them up, there were further rules designed to encourage both the holding of SDRs (as against alternative forms of reserve asset) and also their use as extra last-ditch defences rather than as encouragements to freer spending. ${ }^{34}$ A participating authority was not allowed to use its SDRs in exchange as freely as its other reserve assets. SDRs were designed as extra money for central banks, as it were to keep in the fireplace for emergencies, not in the normal course of events to spend so as to run their reserves down as low as before. One of the restrictions, removed in 1981, was that each authority was required to keep its SDR holdings, on average over a period, at no less than 30 per cent, later reduced to 15 per cent, of its cumulative allocation.

\footnotetext{
${ }^{32}$ Gold, 1970; cited in de Vries, 1976, vol. 1, p. 188.

33 de Vries, 1976, vol. 1, p. 182.

${ }^{34}$ de Vries, 1976, vol. 1, pp. 181-6.
} 


\section{Could the Soros donation proposal work without changes in the rules?}

Could the Soros proposal, very similar to some that had been made earlier, be easy to implement under the present IMF constitutional provisions and administrative policies? Decisions made by the Fund's Executive Board over 1978 to 1980 specifically altered the working practices so that, if the Fund agreed, recipients of SDRs might use them as grants. ${ }^{35}$ Moreover, a global fund set up to receive such grants and dispose of them might, as an executive decision, be named by the Fund as an "prescribed holder", like a handful of other international institutions, and thereby be allowed both to hold SDRs and to trade them with central banks and other prescribed holders in exchange for currencies.

But the interest arrangements have awkward implications for Soros' proposal. This is because those authorities giving up their future allocations of SDRs would presumably at least have to be relieved of the obligation to become net payers of interest for the privilege of doing so.

To overcome the interest problem, it would be possible in principle to re-frame the whole system, so that future issues of SDRs or equivalent were more like a regular currency. This is the general direction in which SDRs were moving under the Second Amendment to the Articles of Agreement in 1978 and other decisions taken about that time. But politically that is not at the moment a promising route. If the Soros Plan were to come into effect tomorrow, someone would have to pay the interest. On the assumption that the immediate beneficiary of future SDRs allocated to the rich countries were to be a global fund, that fund might be required to pay the interest, either directly to the IMF's Special Drawing Account or to the donor government in the form say of an obligation on a bond issued for this purpose. When the global fund wanted to use the assets, or to pass them on, for the purchase of goods and services, it would first need to exchange them for "currencies" (bank balances or short-term securities) with a central bank (or another prescribed holder). The other party would accept the SDRs in exchange for the currency asset - one short-term interest-bearing asset for another - but would not be interested in taking on the interest obligation (the payment due to the IMF or the servicing of the hypothetical bond) with it. The global fund would be left with the obligation as well as the new asset. When it spent the new asset or transferred it as a grant, it would still be left with the interest obligation unless it also transferred this to the authority or agency that was the beneficiary of the grant or expenditure.

The effect would be that, in terms of financial flows, the high-income countries that chose to make over their SDRs to a global fund would be no worse off than if they had not done so. They would have less international reserves in their accounts, but that would probably not be a matter of concern if they were likely to be able to borrow in the short term promptly and cheaply.

So what in effect the global fund would have received from the donor government is a termless loan at a standard short-term interest rate. One possible use of this would be as reserves, another form of the use for which they were designed: a way (costless net) for holding large amounts against contingencies, either still as SDRs or in the form of other assets (with corresponding obligations) traded for them. If the global fund were to provide guarantees, for example, of markets for new drugs or vaccines, these assets could be held costlessly against the call to make good the guarantees without having in that contingency to raise large amounts in the financial markets. Or, if one of the functions of the fund were

${ }^{35}$ Boughton, 2001, p. 933. 
to reduce the debt burden of highly-indebted poor countries, buying out their debt by exchanging it for the proceeds (and the obligations) of SDRs could be valuable to these debtor countries even though it left them with interest obligations at international short-term rates. The servicing obligations would be much more favourable than those attached to many of the loans that might be available to developing and transitional economies (though less so than those on IDA loans): much more favourable probably than those on most of the loans that might be bought out by the SDR proceeds.

But this quirk of SDR arrangements does take some of the attractiveness from the Soros and similar schemes.

\section{Regular issues of SDRs?}

Implicit in the Soros and Zedillo proposals is that regular allocations of SDRs should be resumed.

For purposes of stabilizing world activity at a high level, the ideal would be that these should vary in a countercyclical fashion: high when other sources of reserves are falling or demand for reserves is growing or when the rate of growth of world trade and activity is falling or appears to be about to fall; low or negative in the opposite case. This, however, would probably involve giving some executive unit within the IMF much greater dayto-day discretion than seems within the range of present political possibilities.

A second best might be a working rule designed to meet some specified requirement: such as that: (a) total non-gold reserves should rise at the trend rate of growth of world trade (or of trade and other international "real" transactions); and that (b) SDRs should be adequate to supply this expansion without the need to increase reserves of national currencies (or the, much smaller, quota contribution to reserves). It would be easy to show that a rule such as this was far from perfect. But it would arguably be much better than having no rule at all and leaving the issue to a repeated political lottery. The rule could readily be made operational in such a way as to reduce the need for year-to-year discretion. And maybe simple qualifications could be added so as to make it more useful but no less objective. The goal of making SDRs eventually the dominant element in reserves is embodied in the IMF Articles of Agreement. It does probably make sense, because it means disentangling the supply of reserves from the readiness of certain large countries to keep on spending (and paying out in investment and transfers abroad) more than they produce (and receive in investment and transfers from abroad); and also disentangling the value of reserves from the vicissitudes of exchange rates.

On the assumption of a 6.5 per cent per year growth at current prices of the trade or transactions indicator ${ }^{36}$ and total non-gold reserves starting at the end 2000 figure of SDR 1,545 billion, the rule in simple form would initially involve annual allocations of SDR 100 billion (US\$130 billion at the end 2000 exchange rate), of which, if the Soros rule were followed completely, 61 per cent, US\$79 billion, would be donated to the global fund. ${ }^{37}$

\footnotetext{
${ }^{36}$ It was roughly the rate for the decade ending in 2000, over which non-gold reserves in fact rose in nominal SDR terms at 9.0 per cent per year.

${ }^{37}$ International Financial Statistics, Yearbook 2002, pp. 7, 38-9.
} 
It is perhaps just conceivable that the Board of Governors might agree informally to approve, for a stated period of years, any recommendations on the part of the Managing Director that followed some such rule as this. US concurrence would of course be essential. But permanent US interest against such a move is not unequivocal. Certainly, expansion of the SDR stock touches America closely because of the prominence of US dollar holdings among existing reserves. Cutting the world's dependence on dollar reserves would reduce Americans' access to a deepening well of cheap credit; but there are also grounds for unease from the US standpoint over the risks of the present position. The rule suggested would involve a compromise between these two concerns. There is no particular reason to think that it would lead the volume of dollar holdings actually to fall, but it would remove the need to rely on their unlimited rise.

On the crucial question of United States concurrence, it is worth noting that a decision to create SDRs in itself may be approved by the Administration, without the need to consult Congress; but it seems that a move to transfer the United States allocation of SDRs to a global fund would need Congress's approval. However, failure of the US to make the transfer would not prevent - though it might discourage - other countries from doing so (The moves associated with the 1997 allocation involved two elements that had to be approved by Congress: the change in quotas, which was in the end approved; and the Amendment to the Articles of Agreement permitting the one-off change in the pattern of allocation of SDRs, which was not. Further allocations of SDRs, simply in proportion to the new quotas, may still proceed without the need to consult Congress; so that the block to the unique 1997 allocation would not have to be removed before subsequent allocations were made.). ${ }^{38}$

\section{Is formally altering the distribution of SDRs a possible course?}

The Soros proposal for donations is an attempt to overcome the difficulty that allocation of SDRs according to quota is likely to continue. One of the reasons for supposing that it will do so is the likely difficulty over agreeing on an alternative. It is possible that the best tactic for providing a global fund, if that were to be the overriding objective, might be to leave the formal allocation alone and rely on an informal covenant among the high-income countries such as Soros suggests.

For stabilization, however, the possibility of other allocations might be preferable (one has been allowed, uniquely, under the, so far ungratified, Fourth Amendment of 1997). Though we might not consider, as a near enough practical option, complete administrative discretion over the distribution, there might perhaps be several simple alternatives defined, any one of which, on the Managing Director's recommendation, the Board of Governors might be empowered to adopt for a particular year's allocation instead of universal distribution by quota. For example, there might be an allocation only to low-income and middle-income countries, or alternatively only to countries with more than a certain degree of volatility in their gross foreign exchange receipts, in either case perhaps (to avoid raising another bone of contention) proportionately to their quotas.

A move in this latter direction might admittedly conflict with the impetus and opportunity for Soros-style donations. But it is also possible that, once this possibility of alternative distributions had been accepted, formal allotment of a regular share to a global fund might come to seem a more natural step. This would not mean diverting the SDRs, except temporarily, from nations' reserves. While SDRs can be held only by central banks and a few international institutions, any issued to a global fund for spending on goods and

\footnotetext{
${ }^{38}$ Our interpretation of advice kindly provided by a former Executive Director of the IMF.
} 
services will migrate for the most part to national reserves - either expanding them or altering their composition. This is because it will be necessary for the fund to exchange them for regular currencies before it can use the spending power that they give it. So feeding international liquidity into the system through such a fund will not necessarily affect the aggregate volume and composition of reserves differently, in any permanent and systematic way, from allocating it all directly to national central banks in proportion to quotas.

A power to include certain prescribed holders of SDRs (such as, hypothetically, the Global Fund) in initial allocations would presumably have to be embodied, in addition to the others mentioned, in the Articles of Agreement.

\section{The IMF - a little more like a central bank?}

It would seem then that any adjustment in the direction of formalizing the use of SDR creation (fundamentally designed for stabilization) as a means of sequestering resources for international application (that is, for certain allocative objectives) is likely to require a wider range of discretion for the IMF. This could involve amendment of its Articles of Agreement (its constitution) to provide more powers to its existing governing institutions, and possibly also delegation by them, or further amendment, to give more actual decision-making power to say a technical committee (operating of course under guidelines that the governing institutions had laid down).

Stabilization use would also benefit prima facie from greater flexibility in the creation and cancellation of SDRs and over the way they were allocated among member-countries. Supplying liquidity when and where it is needed to be effective in reducing a selfreinforcing downward spiral in world output and income - or to avert sudden crises of confidence that can bring unexpected disaster to particular countries - may entail empowering the IMF to behave, at least in certain ways, more like a national central bank.

SDR creation, as the historian of the IMF points out, ${ }^{39}$ was designed to meet liquidity needs that were both global and long-term. If liquidity needs in fact tend to be highly country-specific or immediate and possibly temporary, this design makes SDRs as originally conceived a blunt instrument.

When a number of countries simultaneously find themselves obliged to contract because of constraints in their external payments, this is likely to be in a world recession, when prompt measures are needed to restore world demand. Entering such a crisis with a higher level of reserves all round will certainly tend if anything to mitigate the external payments constraints. But their distribution across countries will be all-important. And, because gross world reserves, composed as they largely are of convertible currency balances, do not form a stable, durable aggregate like the world supply of gold ingots, replenishing them in good times will not guarantee that they remain elevated in a recession.

Another contingency in which shortage of reserves matters is that of a self-fulfilling currency crisis, such as may afflict one country at a time, or, through contagion, several in quick succession, as in 1997-99. Then it might be held that extra reserves to discourage the flow are needed - not, however, spread evenly across the world in two years' time, but massively, in one particular place, and today, though maybe only temporarily (it is

${ }^{39}$ de Vries, 1976, vol. 1, p.180. 
arguable, however, that the only satisfactory way by which the IMF can help in such a situation is by credits, not by creating additional reserve media; and also that other measures, of a fiscal character - either in advance to reduce the likelihood of such a crisis or at the time to block it - are better still).

Under the present regime of generally flexible exchange rates, the countries likely to be constrained in adverse world or local conditions by a shortage of reserves are a number of low- and middle- income countries: especially the primary export specialists, but generally those for which modest exchange rate movements either have been ruled out for domestic reasons or are inadequate (because of various rigidities) to make the necessary external adjustments without marked deflation of real demand. It is these countries at these times that can benefit from extra reserve-assets - as liquid and negotiable and "owned" as possible - and can also thereby reduce any deflationary effect that the forced contraction of their economies might otherwise have on the rest of the world.

The use of SDRs for global-priority allocation of resources is necessarily bound up with their use for stabilization. That there should be more flexibility over their initial distribution is a natural requirement for the allocation use, failing awkward and possibly unreliable makeshifts. It could also enable them to be much more effective in getting the liquidity needed on time to the right places, and hence in stabilization.

But, because of the current political climate, we may have to look for expedients less ideal on both scores that are more immediately available.

\section{The burden of using SDRs to sequester resources for global purposes}

Who bears the burden of any resources sequestered through SDR creation for global purposes, say their use in providing vaccines? Who is effectively paying for the vaccines?

Suppose that the SDRs created, though they augment reserves in aggregate, or at least alter the composition of reserves, do not in themselves have any effect on macroeconomic policy, that is on the actions of governments in permitting or encouraging additional spending. The expenditure on the vaccines will, however, increase demand in money terms. How far the vaccines "pay for themselves" by generating additional output will depend on how that additional demand is spread across the world and how far its incidence corresponds with that of unemployed resources.

If all the affected markets are already fully employed, then it will simply add to inflationary pressures and, deliberately or otherwise, the real value of spending on other things will have to be reduced to match in full the value of the vaccines. These reductions will represent the real burden of providing the vaccines.

If, at the other extreme, there is an abundance of unemployed resources in many of the markets affected, the real value of the extra output generated (including multiplier effects) may exceed the value of the vaccines, so that the resources devoted to the vaccines "more than pay for themselves" through the additional resources brought into use. This is even more likely to be the case if, when resources are widely unemployed, the additional reserve-media cast into the system induce macroeconomic policy to become more expansive. Such an effect in itself will increase world output in addition to any increase 
(in private demand and income and resulting government revenue) caused by spending on the vaccines.

So, if, during the onset of a recession, the effect on countries' macroeconomic policies of adding to reserves through extra SDRs, combined with any extra spending on global causes financed by the extra assets, were to increase demand at the right time and with the right distribution across countries, it is quite likely that the extra output created could more than outweigh the value of the resources sequestered to produce the globally chosen goods. Not only could two birds be killed with one stone, but the stone might also pay for itself.

It will be difficult to get the timing and placement of SDR creation, and hence of the spending that it finances or stimulates, exactly right. But, given that there are world recessions, and that countries acting individually, even with consultation among the main players, seem to find it hard to neutralize them, there is surely sense in attempting to come as close as possible to the right combination of timing and distribution of reserve media creation, and of timing and allocation of any associated global-fund spending. And the more closely any allocation of SDRs matches stabilization needs at the time, the less will be the real net cost - to anyone - of using SDR creation to set aside funds for spending on global purposes.

Given that that there is no near prospect that the IMF will be given authority for fine-tuning the timing or the distribution of SDRs, the second-best measures mentioned above - authority for issuing them regularly, failing special reasons to the contrary at any time, according to the likely trend need for reserves on an agreed criterion; and also perhaps the more difficult move of authorizing a few alternative standard ways of distributing them - may be the best proximate steps at which to aim for the sake of stabilization.

\section{Political attractions of using SDR creation to finance spending for global purposes}

As an alternative to raising global funds simply through a national scale of contributions, the use of SDR creation has political advantages. It meets the invisibility test and to a large extent (depending on the precise arrangements) the effort test. As a handmaid of stabilization, it can satisfy the two-bird test. In several possible forms, it could fulfil the demands of the free-rider test.

\section{Steps towards enhancing the use of SDRs in stabilization and in sequestering funds for global purposes}

The following is a graded series of possible moves over SDRs, with the purpose of making them both: (i) available potentially as resources for social and economic development and specifically as funds disposable internationally for global purposes; and (ii) more effective as an instrument of economic stabilization. The moves are ordered by increasing degree of difficulty, those most likely to be politically accessible first, but each is not necessarily a prerequisite for those that follow it.

(a) The already approved Fourth Amendment to the Articles of Agreement is ratified so that the 1997 allocation of SDRs can be made. Alternatively, that allocation is allowed to lapse, and a start is made on further allocations according to current quotas, as can be done under the existing Articles.

(b) The high-income countries (or at first some of them) agree to allot their future receipts of SDRs to an appropriately constituted international body for use in (for example) global public goods and social and economic development. This would 
require of course prior agreement over the constitution and brief of the body designated to hold such a global fund, its naming by the IMF as a "prescribed holder", and also an arrangement by which sums equivalent to the interest received on the SDRs so transferred should be made over (say, through the issue of special bonds by the global fund) to the donor high-income countries in order to offset their obligations to the IMF.

(c) An informal agreement is made by the Board of Governors that they will, for a stated number of years, whenever a recommendation to that effect comes from the Managing Director with the support of the Executive Board, approve an allocation (or cancellation) of SDRs according to a formula designed, for example, so as to make the growth rate of total international reserves correspond to the trend rate of growth of some aggregate of "real" international transactions (such as the sum of imports of goods and services, gross outward transfers, and gross long-term investment) on the assumption of no further change in the holdings of currencies in national reserves (such a rule would accord with the provision in the Articles of Agreement that the SDR was to become the principal asset in the system. ${ }^{40}$ It would also compromise between bowing to the two - opposite - concerns about the volume of dollar securities held in reserves).

(d) To introduce greater flexibility into the use of SDRs for stabilization while allowing the possibility that some might be used for global-priority allocation, the Articles of Agreement are altered to allow: (i) one or more permitted patterns of allocation of SDRs apart from that simply and universally according to quotas (the range of choice, and also the choice made in each round of allocations, to be approved by the Board of Governors on the usual recommendation from the Managing Director backed by the Executive Board); (ii) certain "prescribed holders" to be included in permitted allocations.

(e) For the sake of further flexibility in contributing to stabilization, the Articles of Agreement are altered to give to a technical body, for example, a subcommittee of the International Monetary and Financial Committee, under guidelines and limits laid down from time to time by the Board of Governors, discretion over quantity and timing in the creation and cancellation of SDRs.

\section{To summarize}

* Political moves and informal bargains that seem not completely beyond the range of possibility over the next few years, and do not require the negotiation of further constitutional changes in the IMF, could start the process of implementing a scheme such as Soros proposes by which regular issues of SDRs could be resumed and the high-income countries could make over their allocations to a fund for global purposes.

- The regular SDR allocations could themselves be of value to a number of developing countries that felt the need of enhanced safety margins in their reserves. They would find SDRs a low-cost way of meeting this need - indeed a costless way until they actually disposed of the extra reserves so generated.

- $\quad$ Resumption of SDR allocations on a scale that could be justified by objectives to which the IMF is already constitutionally committed, and would steer a middle course between running down the volume of dollars and other currencies held in reserves and relying on its unlimited expansion, might generate, if there were complete

${ }^{40}$ Boughton, 2001, p. 946. 
compliance by the high-income members in the commitment of their allocations to global purposes, resources for the global fund initially of the order of US\$7580 billion a year.

- Under present arrangements, these funds available for global purposes would in effect be available for spending or transfer as termless loans at standard (Treasury Bill type) short-term interest rates, rather than as grants.

* However, these could be particularly useful to a global fund as reserves held against contingencies, such as having to make good a guarantee to provide a market for new medicines or vaccines meeting certain conditions. Another possible use would be to relieve the debts of certain countries by exchanging them for termless obligations at lower rates.

- Formalizing any such arrangement for contributing to a global fund, however, which could also go along with more flexible use of SDR creation for stabilization purposes, would require further amendment of the IMF's Articles of Agreement.

* Politically the device would meet the invisibility and two-birds tests, and also largely (in certain possible forms completely) the effort test and the free-rider test. So the opposition that proposals of this kind face in a few key countries may be transient.

* Yet, unless and until some other form of SDR or equivalent is invented that is more like a regular currency (or gold), the interest obligation that must be presumed to attach to SDRs 'passed on' (otherwise unrequited) from their original recipients limits their value for global funding and probably suggests that at least some other device in addition should be tapped as a source.

\subsection{Resources available to and through national governments}

There are various ways in which governments might increase the revenue available to them. This section will consider only those involving transnational activities, and specifically measures to reduce the losses of revenue that come about through the mobility of capital and enterprise in a world of independent tax jurisdictions.

Taxes may be "direct" (on persons, such as taxes on income, wealth, or personal holdings of particular assets) or "indirect" (on transactions, such as general taxes on spending or sales, excise taxes, taxes on imports). Here we consider only income taxes - on individuals or corporations - and the concern is with them only insofar as they fall on incomes from capital and enterprise, the most internationally-mobile of the productive resources.

The sources of overall loss of income tax revenue on account of international mobility can be divided into:

- evasion (through the capacity of residents of one country to escape from the need to report income earned in another);

- $\quad$ avoidance (through the availability of tax havens and generally the opportunities for shifting income between jurisdictions); and 
- competitive "tax degradation" (reduction by each country of its direct tax rates or base, or concessions to non-residents, in order to attract investment that might otherwise go elsewhere).

- (Particular countries may gain in income, and even in state revenue, if they offer lower rates, or more generous concessions, than their neighbours. But the collective effect has been likened to the depletion of a renewable natural resource by free-for-all exploitation. Overall such competition will almost certainly diminish revenue. Though it may not reduce income as normally computed, the constraints that it imposes on countries to reduce social spending, or to put more of the burden of taxation onto labour, contrary to the choices that they would make without these constraints, may well have a total impact that can be regarded as reducing welfare.)

In principle, evasion can be overcome by information; avoidance by tighter legislation; and competitive degradation by self-denying agreements. But the solutions, like the problems, interact.

Certain forms of these failings have a differentially adverse impact on the revenues of developing countries. However, blocking the holes in the tax network will mean potential public revenue benefits for all. In itself, making tax systems more consistent in their implementation makes for greater efficiency in the economies affected rather than less. So, it can well be argued, does equal treatment of domestic and transnational investment on the part of a country's investors. Hence there is no compelling reason to think that either of these two classes of move will reduce the total of world income on which revenue can be collected. (Both of them should be distinguished from a general rise in rates of tax on income from enterprise and capital, which may in principle discourage enterprise, and may either encourage or discourage saving. Reduction of evasion and avoidance, or removal of concessional preferences to non-residents, does not imply a general rise in rates of tax and may in fact enable reductions in rates to be made.)

Making sure that public revenue is actually increased in every country might, however, require some arrangements for redistribution, but the measures suggested here will make it likely that most countries, rich and poor, will increase their collections at a given set of rates. The only probable exceptions are those (generally small) territories and populations that have derived much of their income from exploiting the weaknesses of the international tax system. There might be some way of compensating these (otherwise poor) "traditional" tax-havens with a guarantee of increased aid.

Effective revenue collection can hence be regarded as a global public-good. Governments collectively, if they each balance costs against benefits in complete isolation, are likely to fall well short of achieving it. Yet national tax-systems will no doubt continue to be governed independently. We must depend largely on negotiated arrangements for plugging the gaps. However, in some cases unilateral action by a powerful player or group of players may move the process ahead. And it can edge forward incrementally through a mixture of sanctions and persuasion from those parties who see most interest in, or responsibility for, keeping revenue systems equitable and watertight. 
Against such arrangements, there will of course be considerable vested interests: not only those of the evaders themselves (who may or may not be criminals in other respects) but also of arguably legitimate avoiders and of other highly respectable people whose wholly legal income is enhanced by arrangements that facilitate evasion or avoidance. These classes of people will contrive to represent their interests as national interests and their purposes as manifestations of national independence or liberal ideology.

Estimating the revenue foregone as a result of the evasion, avoidance, and competitive degradation that spring from the collective inadequacies of existing tax systems for dealing with globalization typically depend on bold assumptions or a measure of guesswork. Gurtner, ${ }^{41}$ citing Oxfam calculations which assume inter alia that the whole of the difference between: (a) the revenue that developing countries derive from inward foreign direct investments; and (b) what OECD countries as a whole would derive from the presumed income from that investment at their average standard rates of profit tax, is due to competitive degradation, estimates in the late 1990s a loss of revenue to developing countries on that account of about US\$35 billion a year. From the same source, assuming also that all the portfolio capital belonging to residents of developing countries that emigrates evades taxation within those countries' jurisdictions, he estimates the loss of revenue for 1990 through that means of evasion at US\$15 billion a year. Avi-Yonah, ${ }^{42}$ with similarly bold moves (and assuming much higher rates of the taxation in the residence countries) makes implied guesses of the revenue losses to developing countries through portfolio capital emigration that appear to be well over US\$30 billion a year. Such estimates may be highly approximate but still suggest that the revenue forgone is considerable. And they relate to the losses made by developing countries alone. On the whole their loss is by no means the OECD countries' gain; rich countries lose revenue by some of the same deficiencies. (?) "Capital flight" from the United States (presumably emigration of portfolio capital) as estimated for 1980 to 1982 is many times as high per year as similar estimates for the whole of Latin America, ${ }^{43}$ and, passing to a number of non-taxing jurisdictions, the capital concerned is given much the same opportunities of complete evasion as developing-country capital moving to the United States. The US Internal Revenue Service estimates its own losses of revenue on account of the use of tax havens as US\$70 billion a year. ${ }^{44}$ And figures are given below suggesting considerable revenue losses to the US through the avoidance made possible by the fact that income from productive investment is taxed in several jurisdictions. Very broadly estimates point to an annual revenue loss for developing countries at least of the order of magnitude of total ODA, with the loss for the world several times as high.

The proposals considered here depend considerably on the analysis and policy ideas of Vito Tanzi ${ }^{45}$ and Reuven Avi-Yonah ${ }^{46}$. Some may appear difficult to achieve because they would require wide international agreement; but there are others that might well be adopted by a fairly small number of major economies alone, and that in those circumstances could be effective.

\footnotetext{
${ }^{41} 2002$, p. 2.

42 2000, p. 1599.

${ }^{43}$ See Avi-Yonah, 2000, pp. 1588-9.

${ }^{44}$ Owens, 2002, last page.

${ }^{45}$ Especially 1995.

462000.
} 
Income from portfolio investment and that from direct investment raise different questions. One difference relates to their bearing on developing countries. Low-income and middleincome countries are typically net suppliers of portfolio investment but almost invariably net recipients of direct investment.

The measures covered will be divided into three parts: those of general application; those relevant to portfolio-investment income; and those relevant to direct investment income.

They overlap considerably with the initiatives being pursued by the OECD (especially for transparency and exchange of information relating to financial and management services; and for the elimination of tax regimes giving preferences to foreigners) and by the European Union. But they do go beyond the present thrust of those initiatives.

\subsubsection{Measures of general application}

There are four related objectives to be targeted here, all concerned directly with increasing relevant knowledge on the part of tax authorities. Pursuit of the first two for tax purposes will also contribute to the tracking of money laundering.

- $\quad$ First, relaxing bank secrecy rules everywhere to require banks to give information on particular customers and accounts, when the information is requested for legitimate tax purposes by properly accredited and regulated national tax authorities;

- Second, sharing of information, under strict limitations, among tax authorities of any two separate jurisdictions, over particular taxpayers who have, or are reasonably suspected of having, income falling under both jurisdictions;

- Third (an enhancement of the second), a single worldwide system of electronically recorded identification numbers of direct taxpayers, individual and corporate with each number indicating all the jurisdictions in which the person has taxable activities; each person who has been given an identification number liable to be required to reveal it to any tax authority with a legitimate interest; and tax-relevant information on all, by identification number but not by name, electronically available to any tax authority, in some cases automatically, in some cases on request.

- Fourth, voluntary movement, through consultation and mutual assistance, towards common accounting standards, and towards increasingly similar definitions of income for tax purposes.

Progress in the first two of these directions appears to be happening, especially under the auspices of the OECD and the G7's Financial Action Task Force. The OECD is pursuing openness and the elimination of preferences both in offshore financial centres and among its own members. The third and fourth direction seem susceptible to initial action by groups of countries, such as the European Union or the whole OECD, and progressive extension. 


\subsubsection{Measures relating to portfolio investment}

It is much easier to identify and tax income from border-crossing portfolio investment at source than in the country of the investor's residence. So a ready way in principle to prevent evasion of taxation on this income is to tax it at source, whichever authority eventually receives the revenue, or alternatively to pass information on it to the authorities in the relevant country of residence.

A central problem here is the, recently near-universal, exemption extended by high-income countries from tax on bank interest (and in most cases also bond interest) paid to non-residents. Once the United States in 1984 gave up any withholding tax on interest payable to non-resident aliens, other countries competing with the United States for funds found it hard not to follow. This makes the shifting of funds from the rest of the world to high-income countries even more attractive than it would otherwise be. It also removes much of the incentive that might have existed for the investors to declare the income in their home jurisdictions. By this means the authorities in high-income countries are jointly beggaring themselves, each other, and developing countries.

To increase the revenue publicly available for social and economic development, it is taken here to be desirable that all income on transnational portfolio capital should be taxed, and that the revenue from taxing the income of residents of developing countries should go to those countries' governments.

The European Union countries have been pursuing among themselves a compromise, for action by the source countries, between taxing at source and exchange of information.

In 1998, the European Commission proposed to European Union Members a code of conduct for enabling interest payments crossing jurisdictional borders and accruing to individual persons within the European Union to be taxed by the country of residence. This would give each authority a choice between transmitting information on such interest payments originating in its jurisdiction, and alternatively applying a 20 per cent withholding tax to them failing certification that the residence country's authority had been informed of the payment. The code, embodied in a draft Directive, was opposed by Britain and Luxembourg on grounds of competition, Luxembourg stating that it was unwilling to comply unless competing countries outside the European Union did likewise. ${ }^{47}$

It would seem that such a code is not out of the question, and that there is no reason why it should not be extended to cover interest passing to corporations and to residence countries worldwide. But it seems that all major OECD countries, and even a few others, might have to agree on compliance if it were to take off at all. The OECD, also in 1998, issued a Report, endorsed by all its 29 member countries except for Luxembourg and Switzerland, which, among much else, foreshadowed a regime of exchange-of-information to cover the international movement of finance and service income. ${ }^{48}$ In 2002, it issued a further "instrument" on exchange of information, ${ }^{49}$ with the hope of having its codes on

\footnotetext{
${ }^{47}$ Avi-Yonah, 2000, pp. 1654-5.

${ }^{48}$ Avi-Yonah, 2000, pp. 1657-62.

${ }^{49}$ OECD, 2002.
} 
transparency and information-exchange over tax-relevant material observed by the great majority and bulk of offshore centres (many of them tax havens) by early 2006 .

But there is a strong case, and probably an opportunity, for going farther and faster than either the European Union or the OECD, removing some of the limits within which they are operating.

Accordingly, Avi-Yonah ${ }^{50}$ proposes that a withholding tax of 40 per cent should be applied by all countries to portfolio investment income (including royalties and "other deductible payments", such as management fees) arising in their jurisdictions but owned elsewhere, but that this should be refunded in full to any taxpayer who could provide a certificate that the income had been notified to the tax authorities in the country of residence (and, it appears to be implied, remitted, in full or in part as appropriate, if a tax treaty between the parties limits the tax that can be imposed by the source country). The idea is that the 40 per cent rate would often be as high as, or higher than, the marginal rate applying in the country of residence, so that the taxpayer would often have a private incentive (apart from the law) to notify that country's tax office. That authority would then have the opportunity to levy the tax at its own national rate. Because tax treaties already exist between most pairs of OECD members, the main beneficiaries of the measure would be the treasuries of developing countries. ${ }^{51}$ So a tax would be paid. Unlike the proposed European Union withholding tax, this should apply to corporate as well as individual persons, and to residents of everywhere (the withholding tax's application to dividends, though raising slightly different issues from that to interest, royalties, and management fees, should not be excluded.) As a combined effect of law and often an incentive too, the tax would mostly be paid in the end to the country of residence unless a treaty provided to the contrary. The device would be simple. Avi-Yonah explains why exchange of information alone, proposed as an option within the European Union, would not be adequate for the wider world.

Avi-Yonah, rightly or wrongly, regards the existence of "traditional" small (no-tax or low-tax) tax havens as no serious obstacle to the effectiveness of the withholding-tax device - on the ground that they would not compete significantly for funds with the major countries. However, this would be a potential chink in the armour. Hence the device would not obviate the need for OECD and other pressure towards transparency and exchange of information on the part of tax havens.

What Avi-Yonah deliberately avoids recommending is that some test should be applied to the tax policy of the country of residence before the refund of tax is made: for example, that it should require, as a condition of remitting the withholding tax, that the country of residence should impose on its denizens a legal requirement to pay income tax, or even to pay it at no less than a certain standard rate. This would mean that, if the purported country of residence were a no-tax or low-tax tax haven, the withholding tax would not be remitted. It would reduce the capacity of such tax havens to blow holes in the defence of state revenue. Avi-Yonah rejects this position on principle as conflicting with national

${ }^{50}$ 2000, pp. 1667-70.

${ }^{51}$ Morally if not legally, it might be argued, the device could be applied even where a tax treaty precluding tax by the source country existed. The withholding tax after all would not be retained unless the residence country was in no position to collect the revenue due itself. The residence country might at least be given a choice. Tax treaties might by agreement, in order to meet the spirit of their specific provisions, modify what was done in other ways. 
autonomy in domestic fiscal policy, and indeed it seems unlikely to gain wide acceptance. The approaches with an impetus behind them in 2002 are towards openness and the elimination of preferences, not setting a floor to rates.

Avi-Yonah argues that the European Union's proposal should be taken by the United States as a signal that it is prepared to cooperate in a measure of this sort. The European Union dissentients did not after all rule out compliance provided their non-European Union competitors joined in. So there is a historic opportunity for agreement among the main players to remove this huge source of revenue loss, both to themselves and to the developing countries.

\subsubsection{Measures relating to direct investment}

There are two main problems over the effective taxation of income from transnational direct investment.

The first is the absence of clear, mutually consistent, and enforceable rules over how various tax jurisdictions divide their claims on a particular block of earnings made by a transnational enterprise. Tanzi ${ }^{52}$ cites four studies (using evidence on foreign corporations in the US and on US companies abroad) that point strongly to the shifting of declared income between jurisdictions as a significant source of loss of revenue. ${ }^{53}$ This is presumably because the various national authorities are basing their claims on differing rules and consequently requiring different sets of information. There is no check on whether the returns supplied to the various authorities are mutually consistent, and, even if information were shared, that check might be difficult to make. Grounds for judgment about location of the operations on which income is based are not always unambiguous. So the taxpayers have scope for interpreting each claim independently in their favour.

The second problem is the presence of one or more of the following three conditions which indicate that the firm is under-taxed. (a) The headquarters, and therefore the ostensible residence, of the firm, is in a "headquarters tax haven" (a country giving tax preferences to foreign firms establishing headquarters within its territory) or a "traditional" (no-tax or low-tax) tax haven. (b) The production takes place in a "production tax-haven" (where concessions are given to production by foreign residents) - and at the same time the country of residence applies the principle of exemption, rather than credit or deduction, as its device for avoiding double taxation, or alternatively is a tax haven itself. (c) There is no "permanent establishment" in the main jurisdictions where a firm's sales take place sufficient to qualify the firm for tax liability there under the usual conventions.

\footnotetext{
52 1995, pp. 101-3.

${ }^{53}$ For example, in each year from 1982 to 1990, taxable income reported by foreign-controlled US corporations bore between a half and a twentieth of the proportion - either to receipts or to assets of the taxable income reported by other US domestic corporations.
} 
For the first deficiency, Tanzi ${ }^{54}$ suggests that national authorities might apply something analogous to the "Massachusetts formula" that has been used by a number of States in the United States to divide corporate tax liabilities among themselves. This formula bases the tax shares on a composite of the shares in assets, sales, and labour-income that are located in each State. The key requirements would be:

- a declaration, to each concerned jurisdiction, of total world income (as defined by that jurisdiction's legislation); and

- a formula for division of liability based on a few objective indicators.

Any such rule would have an arbitrary element, but it could have the great advantage of being comparatively simple and objective in the tests applied. The taxable entity would be required to give each authority an account of its total operations and of how each of the variables was divided between countries. Ideally, the various authorities would be applying the same rules in defining income for tax purposes and freely sharing information. But the first of these last two requirements is improbable in the near future, and the second is likely to be patchy at best for some time to come. However, if the members of the OECD could agree on a formula - with the weighting, and certain fundamental matters of definition, of the objective variables that would provide the criterion - and would correspondingly require from each taxpayer a return based on total world operations, this would greatly reduce the scope for avoidance.

For the second complex of deficiencies, Avi-Yonah ${ }^{55}$ argues that wide implementation of the OECD guidelines (on such matters as transfer-pricing, credit-based methods in countries of residence for avoiding double taxation together with the inclusion of certain classes of income from foreign subsidiaries of the company taxed, and the elimination of preferential regimes) would go a long way towards plugging the gaps, but even their observance by significant groups of countries would not deal adequately with noncompliers and tax-havens. Even if all OECD members complied, there would be scope for firms to shift headquarters or production to non-OECD jurisdictions that did not. So he proposes in addition a radical device that has the advantage that any significant subset of OECD countries - indeed in most or all cases individual countries - could apply it alone without risk of loss therefrom.

This device is that the jurisdiction in which a transnational firm sells its product (say, to more than a threshold gross value) would apply in the first instance a withholding tax, at corporate tax rates, to the gross value of those sales. The firm might then submit a tax return showing the costs associated with those sales so that the net income they represented could be estimated, and potentially the tax that had been collected over and above what would be due on that income could be remitted. But any remission of the tax on gross sales would be allowed only if either: (a) the firm could show that its relevant production, and its residence for tax purposes, were not located in jurisdictions that gave preferential concessions to foreign-invested production or foreign headquarters respectively (in which case the whole of the withholding tax would be remitted); or (b) it made a full return of the relevant income to the jurisdiction where the sales took place (in which case the excess of the withholding tax over the tax that would be due on that income in the country of the sales would be remitted).

\footnotetext{
54 1995, p. 26.

${ }^{55}$ 2000, pp. 1664-66, 1670-74.
} 
In other words, a firm selling in country A would be required to do one of three things:

- show that it was subject, against the relevant income, to source-jurisdiction and residence-jurisdiction tax regimes that did not give concessions to foreign investment; or

- $\quad$ file a return and pay tax on the relevant income to country A; or

- $\quad$ pay a gross-sales tax at corporate rates on its sales within country A.

The "relevant income" could presumably be taken to represent the proportion of the firm's world income that its sales in country A represented to its world sales. Under the second option, country A would credit against the tax that it would otherwise claim any income tax paid on the relevant income in other jurisdictions.

The idea would be that the value of siting within a (preferential) production or headquarters tax haven should be removed. Certainly, if both the country of production and the country of residence had universally low (or even zero) rates of tax, none would be collected ultimately under these arrangements by the country in which the sales took place, country A (Avi-Yonah is still concerned to preserve domestic fiscal autonomy). A firm might still sustain a rather low total corporate-tax burden by locating its production in Ireland and its headquarters in Hong Kong without incurring penal sales taxes under the proposal. But there is a limit to what can be produced in Ireland. And countries with much scope for production that have general corporate tax rates even as low as Ireland's 12.5 per cent are rare.

If the European Union as a whole, or the United States, or Japan, applied Avi-Yonah's withholding tax on sales, there is no reason to fear that multinationals would cease to sell there. And its imposition by the European Union or the United States alone, perhaps even Japan, would seriously dilute any tax advantage that multinationals gained from location under a preferential regime. We could thus expect gradual diversion of new investment from jurisdictions to which they might otherwise be attracted solely by preferential rates to foreigners. We might also expect the attraction to governments of having a preferential regime, at least for production, to diminish.

However, the tax would represent an ostensible departure from established principles concerning the taxation of a firm's income by a country with which its only connection is to sell its products there. The usual conventions require a "permanent establishment" and taxation only of such income as (with varying definitions) can be attributed to that permanent establishment. As interpreted here, the income tax under the second option would be wider than those conventions would allow. It would be reasonable to have the departure for this specific purpose sanctioned, for example, by OECD members as a body, before particular States applied this device.

Again extra bite could be given to the proposal by interdicting not only preferences to foreigners but also tax rates below a certain level. This might serve to set an effective lower limit to competitive "tax degradation". But it would be contrary to - or at least go beyond - the guiding principles of the emerging OECD conventions. 


\section{To summarize}

- Loss of revenue attributable to interaction among uncoordinated tax jurisdictions probably amounts, for developing countries, to sums at least of the order of total ODA, and, for OECD countries, to much more.

- The losses can be attributed to a combination of evasion, avoidance, and competitive tax degradation.

- The remedies lie in various reforms of legislation and practice, especially in the directions of transparency in financial institutions, exchange of information among tax authorities, removal of tax preferences to non-residents, and application of the credit principle by residence jurisdictions in allowing for tax exacted elsewhere. Pressure and persuasion in these directions is being applied by the OECD and other associations.

- However certain measures that might be taken by particular countries and groups of countries now would accelerate these reforms, or compensate for their present deficiencies, or provide leads for pursuing them more thoroughly and effectively, and in some cases might make large inroads quickly into the revenue losses. These include the following.

- A withholding tax at a reasonably high rate (40 per cent or more) would be applied by all cooperating countries to interest, royalties, management fees, and dividends payable to non-residents, remittable in full to all (other than residents of countries covered by tax treaties with the source country) who could give evidence that the income concerned had been notified to the authorities in their countries of residence, and remittable as appropriate where there were tax treaties. This measure might be difficult to introduce without substantial agreement among the countries hosting the world's main financial centres. But moves recently made within the European Union suggest that the bulk of OECD countries might now be prepared to negotiate among themselves the implementation of such a measure.

- There might be agreement among tax authorities, as widely as possible: (a) to reform their taxation of the enterprise income of multinationals so that each firm would be required to file a return of its whole world income to each jurisdiction in which it was liable for tax, and (b) to negotiate a simple formula, based on a few objective and readily verified variables, for determining the proportions of the total income that would be subject to taxation in each jurisdiction. This reform might be led by a few OECD countries or worked out in a forum such as the OECD. The United States has strong apparent gains to be made from such a reform, as doubtless do many other countries.

- As a radical measure that might be approved by an international forum as allowable for its specific purpose: any country A might apply, to any firm $F$ that had its headquarters and site of production elsewhere and was selling within A's borders, a withholding tax at A's own corporate tax rate on the gross value of F's sales within A. It would be a proviso that: (a) the tax should be remitted in full if $F$ could show that it was not receiving, in any country of production or headquartering, income tax preferences as an alien or non-resident; or, failing that requirement, that, (b) if $\mathrm{F}$ filed in A, a full return of the income associated with its sales in A, the excess of the withholding tax over the income tax due, at A's rates, on that income would be remitted. Any substantial OECD country could apply this device without the need to fear adverse consequences, since multinationals would certainly continue to sell within its borders regardless; and its progressive implementation by countries constituting the bulk of the world market could be expected eventually to eliminate 
tax regimes giving preferences to non-residents and hence remove a large part of the problem of competitive tax degradation.

* A world forum or a significant group of governments might work out a single system of taxidentification numbers through which individuals' or corporations' income tax information could be shared among tax authorities without unnecessarily identifying the individuals or corporations involved and in such a way that the information could be kept anonymous in case it leaked into unauthorized hands. Each number would include indicators of all the jurisdictions in which the owner had tax liability. A person would be required to reveal her, his, or its number to any tax authority that had reason to think that it had claims on the person. Such a system could be adopted gradually as various countries recognized its advantages.

3.3 Resources available to and through local governments

It is important that local governments should be as self-supporting as is consistent with other priorities. Using more fully the opportunities they have for efficient and equitable local revenue raising is likely to give them more genuine autonomy and in particular more capacity to protect their activities against the shocks that globalization and technical change may inflict on the wider national economy.

Here we mention two devices that can be strongly defended on equity and efficiency grounds but are probably not widely used in precisely the forms presented.

\subsubsection{Betterment levies on property owners}

The principle here is that real property owners should be required to contribute, for social purposes, at least a large proportion of any increase in the site value of their property that comes about other than through their own investment. This is clearly equitable, especially when the gain comes through public investment or other public decision such as redesignating land for more profitable uses. It is also an economically efficient way of raising public revenue in that it offers no disincentive to investment (in the economic sense, as distinct from property speculation) on the part of property owners.

In principle, any local tax based on unimproved property values (as generally applied in Australia) - or even on total property values - would take account of gains in value arising from social investment. But, if re-assessment occurs only at long intervals. the opportunity may be missed for a number of years; as a result less revenue is collected in the meantime (or else a greater burden is put on those who have not enjoyed an unearned increment); and a reassessment at the end of say a decade is understandably resented by those who will now be due to pay absolutely and relatively more as a result of site value appreciation, resented particularly since in many cases they will have bought the property since the appreciation in market value has occurred and have consequently not enjoyed all or any of the benefit of the appreciation themselves. In addition, the eventual reassessment, if it does try to take into account relative changes in site-values, is very likely to appear opaque. 
What is needed is some device that, as far as possible, allows extra charges to be imposed promptly and transparently and without undue bureaucratic cost. A number of South American countries accept the principle of betterment levies and have applied them. Colombia had done so in one form or another since 1921, and in 1997 introduced what was called Participación en Plusvalías. This required each municipality to draw up a ten-year plan and to adopt betterment levies as a main source of funding for the plan. ${ }^{56}$ The levies are to be imposed in any one of three circumstances: when land changes category, as from rural to suburban or urban; when additional development rights, relating to density of settlement, are authorized in an area; or when an area changes designated use, as from residential to commercial. ${ }^{57}$ Contiguous areas are marked out, each to be reassessed uniformly.

So the additional levies are to be triggered immediately by specific public-planning decisions; surveys can be used to determine likely changes in market-values by area; and the differentiation of treatment by area, rather than by individual property, limits both administrative cost and the possibilities of favouritism. Hence the three requirements - of promptitude, transparency, and low administrative cost - are likely to be covered.

In Colombia the revenues raised by betterment levies "are to be used primarily for the provision of social housing and infrastructure in under-served neighbourhoods, as well as for public works of general interest" ${ }^{58}$ Clearly, it would be possible to denote various other possible types of change that could trigger extra levies on property, such as improvements in road or rail or telephone connections, or the extension of piped water or electricity networks. But gains from doing so would need to be balanced against the losses from increased complexity. It would on the whole be cheaper administratively, and probably more acceptable politically, as well as more efficient in other ways and more equitable, to realize the relevant part of the gains in most of these other cases through user charges.

\subsubsection{Developers' contributions to social infrastructure}

When permission is given for a particular development project to go ahead (home building, hotels, retail, entertainment, manufacture), it would be reasonable to charge the developer routinely an estimate of the full cost of extra socially provided infrastructure (water supply, sewerage, road capacity, policing, schooling, health service investment) that is likely to be entailed. Developers would thus pay something closer to the full social cost of their investments. This would be economically efficient: what has to be spent on restoring the social infrastructure to the same standard as before is part of the social cost of a commercial development. It would provide resources for avoiding the deterioration of urban conditions that easily accompanies increase in population and activity - and remove excuses for allowing squalor to advance. There is no ground whatever for regarding it as inequitable.

\footnotetext{
${ }^{56}$ Barco de Botero and Smolka, 2000.

57 ibid., p. 4.

58 ibid., p. 4.
} 
It would be important to have standard formulas for determining what was due. This would not only simplify administrative processes but also reduce the opportunities for corruption and favouritism - or for relying on the undertakings of developers to supply specific facilities themselves, undertakings of a kind that may be difficult either to value or to enforce. The fact that a particular investment happened not to require any extension of the sewerage system, for example, should not lead it to be treated differently from one that did actually demand such additional infrastructure. Increasing population must have increasing sewerage. Each new private investment that has the effect of increasing population should pay its share. Formulas might well be promulgated nationally.

\section{To summarize}

- There is often scope for additional efficient and equitable ways of raising local government revenue (especially in towns) through: (a) systematically charging property owners for the increases in site value of their property that arise through planning decisions; and (b) charging prospective developers for the probable costs of the additional social infrastructure that their investments can be expected to require.

- Transparency and the minimization of administrative costs in the implementation of these measures depend upon the use of simple, standardized rules for determining the charges in each case: for example, standard rates per unit area for the rise in site values, each applying over a significant area; and standard costs of additional social infrastructure entailed by any type of investment, with, say, a coefficient particular to the kind of investment (housing, offices, sport, entertainment, retail, hospitality) applied to the amount invested.

\subsection{Resources available through community mobilization}

Voluntary labour, care, and ingenuity may be made available free of charge to community projects if: (a) an initial vision and trust can be created; and (b) structures can be set up which ensure that contributions are not wasted, that all contributors are likely to benefit, and that there is universal participation by contributor-beneficiaries in the control of the ventures.

No doubt many examples could be given. Two - fairly well-known and catalogued examples are given here. These are the Orangi Pilot Project for providing sewers in a deprived and neglected part of Karachi, ${ }^{59}$ and the transformation of the Gal Oya irrigation settlement in South-Eastern Sri Lanka. ${ }^{60}$ They are notable not only for their large scale and the special lessons that seem to follow on that account, but also for what they reveal about the capacity of people in unpromising circumstances for constructive and responsible endeavour.

\footnotetext{
${ }^{59}$ World Bank 1992, p. 109.

${ }^{60}$ Uphoff, 1996.
} 


\subsubsection{Sewers in Karachi squatter settlements ${ }^{61}$}

When Akhter Hameed Khan began working in the Karachi settlements, he found that a priority for the people was removal of excreta and wastewater from the streets. They wanted a traditional sewerage system and they wanted government to provide it. When attempts to achieve this failed, the Orangi Pilot Project was started with a little outside funding. The business of providing the sewers was undertaken by the people who were to use it. At the time of the account, about ten years after the start of the project, more than 600,000 poor people in Karachi had been supplied with adequate sewerage services at a cash cost of less than US\$50 per household.

The achievement seems to have been due to a combination of innovative techniques devised by the engineers and architects on the project; the elimination of corruption and slackness associated with government operations; the supply of free labour by members of the community; and eventually a community organization with enough influence to induce cooperation from the municipal authorities, which extended the trunk sewers, and enough staying power to see that they were maintained. Community inputs and control, while not the whole story, were clearly crucial.

The community's support was mobilized and its control exercised through a "nested" or "federal" structure of residents" organizations. Each unit of the "lowest" level of organization (based on the "lane") consisted of about 15 households, who elected a "lane manager". Lane committees elected members to neighbourhood committees, each of which covered about 600 households; and so on up. This structure corresponded apparently to the tributary form of the sewerage system. There was a committee to see to the maintenance of each branch and twig.

\subsubsection{Water management in a Sri Lankan irrigation project}

At the end of 1980, the Gal Oya Left Bank was part of a huge and troubled irrigation settlement in Sri Lanka. It had over 20,000 farmers who had been settled there from a variety of areas and both major language communities, many of them regarded as troublemakers in their places of origin. The system was managed from above by officials, and the farmers were notoriously uncooperative. There had been much destruction of irrigation facilities and neglect of necessary maintenance. Irrigation officials in charge were commonly remote and arrogant towards farmers, and also negligent, and a number were believed to be corrupt. Water was used very wastefully, and about one-third of farmers situated downstream got no irrigation water at all. Tamils, who were a minority in the area, were represented disproportionately among these unfortunate "tailenders". There was considerable mutual hostility among farmers over water disputes.

The Gal Oya Water Management Project, starting in March 1981, took place under the auspices of a government research and training institute (ARTI) and a foreign NGO (a unit of Cornell University), with finance from USAID. The aim was to improve water

61 This account draws its information from the two sources cited above, and largely reproduces passages in a paper that was written by the drafter of the present document for the UN Secretariat as part of the preparatory process for the World Social Summit of June 2000. 
management through bringing farmers to participate in it - with more cooperative behaviour among farmers, and as a result improved performance of local officials. A key element was the appointment of (initially 32) "institutional organizers" (IOs), young graduates from farming backgrounds, who would be allocated in small groups to particular parts of the scheme, would get to know the farmers, and gradually, it was hoped, would inspire the creation of farmers' organizations.

These organizations were built up from below, eventually into a structure with four layers, representing the hierarchy of connections within the irrigation network. The lowest level (each unit associated with a field channel), the first to be established, was small enough for personal acquaintance and meeting among the farmers it covered. In this nested or federal structure related to the physical shape of a network, there are similarities with the Orangi project.

The project met at first with varying hostility and scepticism among officials. It also started in a specially bad year when water was unusually low and conflicts might have been expected to flourish.

Yet, within six weeks, 90 per cent of farmers in a pilot area over 2,000 hectares were voluntarily undertaking a programme which they devised themselves, with organizers' encouragement and facilitation. They cleaned channels, some of which had not been cleaned for 15 or 20 years; rotated water deliveries, so that tail-enders would get a fair share of the available water; and saved water wherever possible to donate to farmers downstream who would otherwise receive little or no supply. Such demonstrations of altruism and cooperation are generally considered unlikely. They were quite remarkable because Gal Oya farmers, resettled into the area two or three decades earlier, had previously been known for their conflictual and individualistic behaviour, "even murders over water". ${ }^{6}$

And the process continued and spread over the project area, with concrete and measurable results. "Within five years, water use efficiency had almost doubled in the Left Bank system". ${ }^{63}$ At the same time the chief generalist official in the District is quoted as saying that previously he had had about 200 complaints a week about water problems but that by late 1984 "not a single farmer comes to complain to me about water problems". The same available flow of water, properly husbanded and distributed, had proved enough to satisfy virtually all farmers, the majority of whom had regarded themselves as short of water before.

Yet these material achievements (continuing in essentials at least until March 1996 shortly before the second edition of the book went to press) are perhaps no more remarkable than the changes in attitudes that lay behind them. It was not uncommon for upstream farmers to go out of their way, getting up at night for example, to make sure that the system of conservation worked, so that downstream farmers would get their share of water. Local irrigation officials came as a matter of routine to treat farmers with respect, and became far more diligent and helpful. Most striking of all are the efforts made on several occasions by

\footnotetext{
${ }^{62}$ ibid, p. viii.

63 ibid, p. 9.
} 
Sinhalese farmers to protect the persons and property of Tamil officials, farmers, and fishermen in the face of ethnic violence. ${ }^{64}$

\subsubsection{Conclusions from the projects}

Schemes such as Orangi and Gal Oya are successful in part through being able to by-pass the government. Not only do they not depend directly, to more than a limited extent, on the public finances, but they also escape the corruption, waste and cynicism that frequently go with government operations. They enlist not only people's free labour but also their interest, enthusiasm, and ingenuity. Because they depend on general cooperation, they have to develop a form of organization that will make cooperation work, and this process can have valuable by-products, as Gal Oya shows.

A special lesson from these two projects is that it is possible to have general participation in the control of a large project, with 20,000 households in one case, perhaps 100,000 in the other. Elinor Ostrom, ${ }^{65}$ in considering Gal Oya and similar ventures for managing a common natural resource through voluntary cooperation, stresses the importance of a "nested" or federal form of organization when the number of people involved is large. Both Orangi and Gal Oya, because of the branching character of the systems to be built or nurtured, lent themselves easily to this structure. It seems that in each case the lowest level of organization (the lane or the field channel) was small enough for face-to-face acquaintance among the participants. No doubt it was crucial that all the households should be able to participate in control - as all were needed to contribute and cooperate. In fact, cooperation was required at each level. In the circumstances, the federal structure made both participation and coordination possible.

But can government do anything to help bring such projects into being? First, it can as a matter of policy avoid obstructing: giving such schemes the official approvals they need when they are plausibly proposed, and authorizing official cooperation with them in any of the many fields in which they may have a role. Second, there is frequently a vital input that the state can provide without taking initiative away from the community: dealing with the trunk-sewers in the case of Orangi, providing the services of the institutional organizers in Gal Oya. Third, because success often depends on a combination of community and government, with an NGO as initiator and catalyst, there might be regularized government contact with those NGOs likely to spark community initiatives in social development, so that all three parties might make their appropriate contributions if any such move was planned, and government might ensure that it would be if anything a facilitator and not an obstacle.

\section{To summarize}

- There are large potential gains to be made, both material and immaterial, if some of the kinds of social facilities normally delivered and run hierarchically by governments or by large firms can instead be substantially generated and managed through unpaid labour and enterprise provided cooperatively by the people who will benefit from the facilities.

\footnotetext{
${ }^{64}$ ibid., pp. 76, 101-2.

65 1990, p. 189.
} 
- Because such cooperative participation generally requires face-to-face contact within each controlling or managing group, large projects of this sort are likely to need a "nested" or federal structure

- Government may contribute in these cases by being ready to give the necessary permits; by authorizing official cooperation; often by supplying some critical input; and by regular contact with NGOs that have the potential for sparking such ventures.

* It is important in such cases that all the provider-beneficiaries have the opportunity and encouragement to participate in control.

\subsection{Resources available from private charity}

The question faced here is how to attract more private wealth (especially more of the big hoards, such as the recently estimated US $\$ 8.37$ trillion held in private fortunes of more than US\$30 million each) into global priority areas of social spending.

The device that will be considered here, as a possible way of encouraging more of this wealth to be disgorged as philanthropy, or more of the philanthropy to be available for global priorities, or both, is the institution of what have been called "multisectoral global funds" (MGFs). These are exemplified by the Global Environmental Facility (set up in 1991); the Vaccine Fund (associated with the Global Alliance for Vaccines and Immunization); and the Global Fund to Fight AIDS, Tuberculosis and Malaria (started in 2001).

They have been defined ${ }^{66}$ as global funds in which there is participation, on the one hand, by: (a) national governments or international organizations; and, on the other hand, by (b) the so-called private sector, or NGOs, or educational or specialized research institutions. It is in this sense that they are "multisectoral". "Participation" can be interpreted to cover a role in the management and control of the fund, or as a contributor, or both. The private sector covers charitable foundations; corporations and industry groups; and wealthy individuals and the general public as donors.

Normally each of the MGFs will be established to cover a particular area of concern. This can be highly specific. In the Vaccine Fund, it is the immunization of children. A possible hope is that the specificity - often to an objective of obvious need or indeed urgency combined with other features, may attract potential donors who would not otherwise contribute to meeting this category of need. Among the other possibly relevant features are the fact that the fund is not controlled directly by a government or governments or an intergovernmental organization; that (initially) it has no past failures or alleged failures to dog it; that (if all goes well) it has only a small bureaucracy and the apparent capacity to act quickly; that at the same time it has access to relevant expertise from a number of quarters; that it has the apparent potential to play a substantial, demonstrable part in some great and momentous undertaking; and finally that big contributors may well be given some part in the control of the fund. If all or most of these attributes are present, or appear to be present, a large private donor may have the sense of confidence that comes from knowing, in fairly concrete terms, the purpose for which any contribution will be used, and

${ }^{66}$ Heimans, 2002, p. 3. 
the weight and importance of that purpose - a set of impressions not so readily derived from a fund directly under a government or one of the existing large multilateral bodies, or even perhaps from any particular charitable NGO.

That at any rate is the hope. Perhaps most likely to attract people who have big fortunes at their disposal, people who are often highly achievement oriented, is the prospect of actually solving a major world problem - malaria, clean accessible water, rehydration doses - in foreseeable time. The Vaccine Fund is an ideal example: with objectives that are readily quantifiable; operations that depend heavily on sheer funding and logistics, as against the subtleties and imponderables that dog so many other endeavours; and the possibility of eliminating certain diseases from particular countries or even the world. And the Gates Foundation - fruit of an archetypal entrepreneurial trajectory - is providing three-quarters of the present finance.

In principle, there is always a risk that headline-grabbing achievements will crowd out the less dramatic work that must go on continually. Governments may not always make their contributions to MGFs "additional" to their normal contributions in ODA and to international organizations. Yet headline-grabbing achievements - in health, for example may provide an advanced platform from which other activities can go forward: increased income, less orphans, more able-bodied workers, more taxable capacity, clinical and hospital resources less strained. And, if more of that US\$8.37 trillions in huge fortunes can be mobilized, it is likely to be genuinely "additional".

Jeremy Heimans ${ }^{67}$ has made clear some of the difficulties and hazards of the MGF path. He has highlighted, for example, the problems of reaching a workable constitution for the Global Fund to Fight AIDS, Tuberculosis and Malaria, a constitution that must also be acceptable to all the stakeholders, who may have prejudices as well as legitimate concerns. At the same time, funds need to be able to draw from their stakeholders and others the best available strands of the relevant technical expertise, and to allow for the emergence of leadership and direction.

Clearly particular conditions are required to make such a fund a reasonable response to the need - as well as a draw for large private contributions. But the route has been opened. If it proves successful, other vehicles may follow.

\section{To summarize}

- Applied to suitable purposes, multisectoral global funds (MGFs) may have the potential for attracting large private fortunes - to combine with multilateral, government, and other funds - for the sake of decisive attack on some of the world's major definable deficiencies, such as of disease control, literacy, or water-supply.

- Characteristics that seem most likely to be attractive to the holders of big fortunes are: objectives that are easily quantified; operations with well-tried techniques that depend heavily for success on simple funding and logistics; and prospects of visibly momentous achievements within a decade or two.

- A major challenge for MGFs is to reach a form of constitution that allows all major stakeholders to have influence; that makes it possible to draw on the various sources of relevant expertise; and that nevertheless gives scope for leadership and consistent direction. 


\subsection{Resources available from commercial enterprises}

Here we are concerned with ways not of realizing additional public revenue but of using a relationship with commercial enterprise to make the use of existing public funds more effective. As an example, it appears that MGFs have been able to use the involvement of large firms to negotiate mutually favourable purchasing contracts and to use existing distribution networks and expertise. ${ }^{68}$

\subsubsection{Pre-commitments to providing markets for the products of private research and development}

A major proposal is that public funds might be used to give advance guarantees of markets, at a certain price, for drugs or vaccines that could meet stated requirements of effectiveness. ${ }^{69}$ For example, "the new Global Alliance for Vaccines and Immunizations, which is funding vaccine purchases, could precommit to spend US\$10 per dose for an effective TB, malaria, or AIDS vaccine".: 70

This idea reflects the recognition that: (a) it seems inevitable to rely on large private firms for the huge outlays and organization needed to develop specific drug or vaccine solutions; while at the same time (b) diseases confined to poor countries (or of much less importance in rich countries than in poor) attract very little research in relation to their overall importance for welfare. For example, while total biomedical research is estimated to amount to US $\$ 42$ per disability-adjusted life year (DALY) lost as a result of the diseases at which the research is directed, malaria research rates only US\$2.2 per DALY lost. ${ }^{71}$

The payments would not have to be made in advance of the R\&D. They would not necessarily need to be made entirely out of globally managed funds; national governments could be expected to contribute. In a sense making the offer would be using the funds available for leverage of additional resources to meet the priority needs. Without the commitment, neither the private firms, nor the public funds available, would produce the desired outcome.

Another way of seeing it is that the result of the R\&D would represent a public good. The public authority would not supply the good alone because of the uncertainty of the technical outcome, the lack of politically acceptable opportunities for pooling this risk with others, and the lack too of the specialized technical expertise, risk-assessment experience, and organization. The private firm would not supply it without a guarantee because of the uncertainty of the technical outcome compounded by uncertainty over the market. The guarantee would: (a) remove the second uncertainty from the firm; while (b) not imposing on the public authority the politically unacceptable risk that it might have to pay without being able to deliver; and at the same time (c) providing that the R\&D would be done by the agency more competent to perform it.

\footnotetext{
${ }^{68}$ Heimans, 2002, pp. 26-7.

${ }^{69}$ Sachs, 1999, p.17; WHO, 2001, pp. 84-5.

${ }^{70}$ WHO, ibid.

${ }^{71}$ WHO, 2001, p. 79.
} 
The principle of precommitment might be applied to the results of $R \& D$ other than in health, for example in crop production or building techniques.

\subsubsection{Subsidy to reduce the price of patented drugs (or other inventions) without reducing the incentives to $R \& D$}

Various compromises have been adopted, especially under the recent WTO regime, to leave drug companies with much of the advantage of their patent protection while making the patented drugs or analogous generics available in poor countries at close to the marginal cost of production.

An example cited of the difference in price entailed by patent protection is that recently fluconazole, a drug used to treat cryptococcal meningitis, one of the diseases common among people with AIDS, cost US\$14-25 for a daily dose where its inventor, Pfizer, had exclusive rights to sell it, but only US\$0.75 a day where there was competition. The difference was said to be a matter of life and death for hundreds of thousands of people with AIDS. ${ }^{72}$

The Trade-Related Aspects of Intellectual Property Rights (TRIPS) Agreement, to which WTO members are in principle committed, has escape clauses allowing certain relaxations of patent protection for the benefit of poorer countries; but these have been held to be inadequate, and in any case countries disposed to take advantage of them have sometimes been subjected to punitive measures by the drug companies' home governments.

It might be cost-effective - as a price for expansion and clarification of these rights - for a public authority sometimes to offer a subsidy on the sales of certain patented drugs at marginal cost prices in poor countries.

\section{To summarize}

- Research and development of vital interest to poor countries might sometimes be most efficiently and effectively generated, especially in the health field, with the help of a precommitment on the part of a public authority to provide a market of a certain size at a certain price to a firm that could offer for sale a product meeting stated criteria of effectiveness and price.

* Sometimes a subsidy on the sale of patented drugs in poor countries on condition that they are sold at a price close to the marginal cost of production might be the most cost-effective way of providing the drugs to people who need them without impairing the incentives to research and development.

\footnotetext{
${ }^{72}$ Pecoul et al, 1999.
} 


\subsection{Resources available through the intermediation of NGOs}

NGOs may have a number of roles in increasing the availability of resources for social development, including that mentioned in section 3.1.4 above under the heading of mobilization. We shall deal here only with the provision of microcredit to poor or very poor borrowers for productive investment. In this the role of NGOs has often been crucial in providing intermediaries between small borrowers, on the one hand, and, on the other, the institutions of the State, commercial financiers, and philanthropic (often foreign) donors.

To many people it is almost axiomatic that microcredit (in this sense in which the term has come to be widely understood over the last two decades) is eminently valuable and that the formula for its delivery is now well attested. But there have been dissenting voices, at least questioning some of the claims that have been made. We shall submit that the favourable view is fundamentally right, even though: (a) assertions sometimes made in support (about the self-supporting character of the programmes) have to be qualified; (b) there are a variety of methods of delivery that can claim success in certain circumstances; and (c) the evidence for a substantial impact on production, consumption, or welfare has to be partly anecdotal and partly indirect (with an a priori element) because of the weakness of systematic survey evidence.

By the end of 2001 there were estimated (from returns submitted by lending agencies and recorded in the Microcredit Summit Campaign +5 report) to be 54.9 million people who could be classed as microcredit borrowers across the world, of whom 26.8 million had been among the poorest people at the time of their first loan. Tallies of microcredit borrowers generally include people in Asia, Latin America, Africa and North America, but overwhelmingly in the developing world. A rough estimate about this time was that there were about 10 million micro-borrowers in Bangladesh alone, including about 3 million each from the three biggest lenders, the great bulk of these from among the poor - by the very low national standards. Estimates for a few years earlier suggested nearly 3 million in Indonesia, ${ }^{73}$ though with less concentration on the poor. With 25 million poor households borrowing, 100 to 150 million individuals might be affected. For end 1997, a comparable figure (from the same source as reported the 26.8 million from among the poorest in 2001) came to 7.6 million. This implies a 3.5 -fold increase over the four years, a 37 per cent per year rate of rise. Though it would be naïve to expect this rate necessarily to continue, it is of interest that its projection would give a figure of 93.8 million borrowers from among the poorest households by the end of 2005 .

The Grameen Bank of Bangladesh, which had about 2.1 million borrowers at the end of the 1990s and about 3 million in 2002, is commonly regarded as the pioneer. It has set the popular stereotype of microlending, with its concentration on the very poorest (in principle, though not always in practice, insisting that its borrowers have no more than half an acre of land); its strong bias towards women clients; the fact that it does not require collateral; its organization of borrowers in "solidarity groups" of around five people who take responsibility for each other's obligations; its bait of further loans ("progressive lending") to clients meeting repayment schedules; and its very low rate of defaults. As mentioned below, not all of those institutions regarded as microcredit lenders have an exclusive direction to the poorest. Most, but not all, do have at least some bias towards

\footnotetext{
${ }^{73}$ Morduch, 1999, p. 1574.
} 
women. Most do not require collateral, but again that rule does not apply throughout. Solidarity groups have been widely copied but provide only one model of those used for promoting discipline among borrowers. Progressive lending, however, if not universal, is very nearly so. And, in almost all programmes, rates of default do appear (at well below 10 per cent) to be very low by the standards of most small institutional lending in developing countries before the 1980s. ${ }^{74}$

The Microcredit Summit held in 1997 adopted the target of 100 million poor borrowers by 2005, which might mean in total about half a billion people affected. Extrapolating to the poor of the whole of South, East, and South-East Asia from the proportion of poor households drawing on microcredit in Bangladesh even in the mid-1990s (about 20 per cent of the total of poor households or 25 per cent of rural households ${ }^{75}$ would suggest that the target number is not intrinsically unattainable (more recent advances in the numbers borrowing in Bangladesh imply that by now - 2002 - about 30 per cent of poor households are covered). But, as the figures above show, to register 100 million of what had been initially the poorest people as borrowers by the end of 2005 would require slightly more than a continuation of the extraordinarily fast rate of growth that took place from 1997 to 2001. Morduch's assessment as of the late 1990s was that programmes accounting for the great bulk of the borrowers, especially of the very poor borrowers, were not fully selfsupporting financially. This would have suggested that, without changes to the way in which microcredit to the very poor was commonly delivered, significant further subsidies or donations would be needed for any big expansion. But, one way or another, a very large proportional and absolute expansion seems to have occurred, and even continuing its absolute rate (possibly a defeatist aspiration) until about 2016 would meet the 100 million target.

The term "microcredit" has mostly been applied to lending concentrated on the very poor, but the category is not rigid. Of the numbers cited for the late 1990s, about 2 million were small borrowers from the Bank Rakyat Indonesia, which is a successful commercial bank and does not confine or particularly direct the lending of its small loans arm to the poorest. In fact, those microcredit lenders whose operations are financially completely self-supporting, at least until very recently, appear on the whole not to have been targeted primarily and predominantly on the poorest of the poor. ${ }^{76}$ On the other hand, a survey reported in 1998 of a large sample of microlenders showed that those whose operations then covered a broad spectrum of borrowers (from poorest to those above the poverty line) were more commonly self-supporting than those concentrating at either end of the scale; on average the 28 lenders classified as targeted on a "broad" group by income (out of a sample of 72) just broke even. Altogether the microcredit programmes sampled there covered 83 per cent of their full costs ${ }^{77}$ (this sample, to judge from the total number of borrowers represented, cannot have included any of the largest programmes).

Near the end of the 1990s, of the three huge microcredit institutions in Bangladesh (Grameen Bank, BRAC and ASA, all of them NGOs, and together lending then to between 4 and 5 million, as against about 9 million in 2002), only one, then the smallest, ASA, was

\footnotetext{
${ }^{74}$ This is an attempt to summarize material in Morduch, 1999, passim.

75 Asia Pacific Rural Finance, 1997, p. 9; Getubig et al., 1997, p. 54; both cited in Goodwin-Groen, 1998, p. 3.

${ }^{76}$ Morduch, 1999, pp. 1574 (Table 1), 1610.

77 ibid., pp. 1584, 1588.
} 
even arguably financially self-supporting, ${ }^{78}$ and it is not clear whether the definition of financial self-support used in this source includes the capacity to be profitable without any donations or subsidized loans received. On the other hand, Morduch ${ }^{79}$ who appears to be using the most demanding definition, estimates that the Grameen Bank could have broken even, in the early 1990s, if it had raised its average lending rate of interest from less than 20 per cent to 32 per cent (nominal) without thereby losing custom. Given that BRAC, with about 1.5 million clients, of a similar character to Grameen's, was charging 30 per cent nominal, Morduch thought it possible that Grameen might maintain its volume of lending with the higher rate of interest, and (using the example of ASA) that, in addition or alternatively, it might be able substantially to cut its costs. Assertions were made in 2002, from within Bangladesh microlending circles, that BRAC and Grameen as well as ASA were by then fully self-supporting; but it is difficult to be certain of what exactly was meant.

Probably it can be said that institutions with the bulk of clients, and a much greater proportion of very poor clients, have not, at least until very recently, been fully self-supporting financially. But, even if they are still not so in the most rigorous sense, it is not out of the question that, by raising interest rates, or reducing costs, or expanding client numbers, or some combination, they might become so. This could on the face of it enable them to raise funds in the financial markets and remove the financial limits on expansion. The longer term after-effects of any large expansion are likely to include reduced overhead costs per dollar on loan. Yet any large and quick expansion of numbers of lenders focused on the very poor is likely to involve big initial costs of administration and training, with delayed returns; and it is hard to see these as happening without government subsidy or some form of donations or subsidized loans. So we are likely to continue having, as the more important actors, first, profit-oriented banks, such as Bank Rakyat Indonesia and Banco Sol in Bolivia, with programmes specializing in small loans but including loans to the poor in their portfolio; and, second, non-profit oriented NGOs concentrating on the very poor. The latter group may manage eventually to become financially self-supporting but will probably require grants or subsidized funds for starting up and for any large spurt of expansion. It is best perhaps not to base the case for microcredit to the poorest on the supposition that it can be everywhere and always fully self-supporting to the point of being able to rely entirely on commercial sources of funds.

Reliable hard survey evidence of the gains made by very poor households as a result of micro-borrowing appears to be scarce. Morduch ${ }^{80}$ cites results that purport to show, for a variety of lenders, across-the-board rises in income of borrower groups in relation to controls (they seem to show, also, that the least subsidy-dependent lenders produce the highest relative rises in income). However, some of these rises are very small; oddly the initial incomes of the borrower groups are generally higher, often much higher, than those of the controls; and Morduch gives reasons for doubting the care with which this particular study was conducted. On the other hand, literature about the Grameen Bank from its early days has produced much, highly plausible, anecdotal evidence of the difference that its loans have made to people's lives. And, where huge numbers of people, many of them very poor by all standards, are willing and able to borrow and repay, and to continue borrowing and repaying, at what Europeans with house mortgage loans would consider quite high rates of interest, it is surely reasonable to think that they are thereby increasing their measurable income through investment, and moreover that they are increasing their welfare as they themselves judge it.

\footnotetext{
${ }^{78}$ Goodwin-Groen, 1998, p. 8.

79 1999, p. 1591.

${ }^{80} 1999$, pp. $1600-1$.
} 
That some of the outstanding amount of this lending to the poor has to be subsidized - to the extent one-off, say, of a part, or even the whole, of its capital value - by the State or private philanthropy can surely be acceptable. The very poor can justly make a claim to have their position improved at the expense of the rest. The difficulty with so many of the ways of channelling funds to very poor people is to ensure that what is made available really does sustainably increase their material welfare as they themselves judge it, and this is what microlending appears to do. Prima facie, it is a particularly effective way of using any free or subsidized capital available for their benefit to invest it in a revolving fund from which resources can be drawn to be put at their at their disposal for their own priority uses, uses that must on the whole (if they are to keep on borrowing and repaying) entail productive investment.

At the end of a highly cautious and critical review of the evidence and debate on microcredit, Morduch begins his conclusions by saying that, through the microfinance movement, "poor households are being given hope and the possibility to improve their lives through their own labour". The movement, he also says, "has shown that [...] in some cases it is possible to lend profitably to low-income households", while at the same time "the programmes are highly cost-sensitive, and most rely on subsidies" ${ }^{81}$

Clearly NGOs have had a large part to play in all this, even if they do not provide the only useful vehicle. This is especially so when there is to be deliberate concentration on the very poor. NGOs have been able to employ government funds while keeping the government at arm's length from operations. Far more than governments, they have also had the credibility to attract private donations. The three big microlenders in Bangladesh, which account for perhaps a quarter to a third of the world's very poor microborrowers, are NGOs. Yet it is not out of the question that institutions such as these will be able to draw increasingly on the financial markets for their expansion. In addition to, or perhaps in part explanation of, their other advantages, Morduch concludes that: "NGOs have had the energy, dedication, and financial resources to pursue legislative changes and institutional experimentation". 82

Governments, foreign donors - perhaps in time the financial markets more widely as well - may provide the funds. Suitable NGOs seem to be necessary as a rule for transmuting these into sustainable and progressive welfare gains for the very poor.

* Recently about 55 million people worldwide, 27 million of them originating from among the poorest - in Asia, Africa, and the Americas - have been microborrowers at any one time, representing probably four to six times as many household members. In Bangladesh alone, there have been around 10 million households with loans outstanding, including among their number perhaps about 30 per cent of all poor households. These figures, combined with the very high rate of growth recorded worldwide of numbers of borrowers from among the poorest.between 1997 and 2001(a 3.5-fold increase), suggests that a target of 100 million borrowers at any one time from this category is not intrinsically unattainable within say the next decade, even if its achievement as hoped by 2005 would demand a huge concentration of effort by governments, donors, and NGOs.

\footnotetext{
${ }^{81} 1999$, p. 1609.

82 ibid.
} 


\section{To summarize}

- Non-governmental organizations (NGOs) have various roles in social and economic development. One of the most striking has been to serve in the provision of microcredit: as intermediaries between governments, donors, and financiers on the one hand and poor borrowers on the other

* The modes of operation and outcomes of institutions defined as microcredit lenders have displayed a variety of characteristics, but universal or nearly so have been: (a) the use, as an incentive, of the prospect of further loans for people who have observed repayment obligations; and (b) very low rates of default. Repeated repayments and further borrowing by poor people must mean that the borrowers are generally increasing their material welfare as they assess it, and that they are doing this sustainably through investment.

- Some of the institutions lending to poor people have managed to be fully selfsupporting financially, and of these some have been profitable commercial businesses; but those concentrating on the poorest have generally had to rely, at least until very recently, on some subsidy in the provision of capital, and these, including most of the largest microcredit lenders, have been NGOs.

- Nevertheless, some of the biggest NGO microlenders, with a strong concentration on the poor, seem either now to have reached self-supporting status, or to require for it only some possibly attainable combination of higher interest rates, more clients, and a lower scale of overheads.

* It seems likely, however, that start-ups, or rapid expansions, with concentration on the poorest, will continue to need an element of subsidy.

* Yet a degree of subsidization seems in principle perfectly acceptable if it is applied to ventures that provide some of the poorest people with sustainable improvements in material welfare as they themselves judge it - and if there are not more efficient ways of using the resources involved to the same ends. 
- The NGO microlenders may be regarded on the evidence as catalysts that perform the task of transforming government subsidies, private donations, and commercial finance into opportunities for freely chosen forms of welfare improvement on the part of very poor or poor people, which those people have the opportunity to attain through their own work, creativity, and discipline.

\section{Anthony Clunies-Ross}

* So financial self-sufficiency in future transactions may well be an object of aspiration among NGO microlenders, not least because it would give potential access to huge sources of commercial funds that would otherwise be unavailable, but it should not be pursued as an overriding priority and certainly not regarded as a precondition of public sector or charitable support. 


\section{Bibliography}

Anthony, I, P.D. Wezeman and S. T. Wezeman. 1998. "The volume of transfers of major conventional weapons, 1988-97", in SIPRI Arms Transfer Project, updated 17 July 1998: http://www.sipri.se/projects/armstrade/imp_exp_regional_88-97.htm1

Asia Pacific Rural Finance. 1997. 9(5), January-March; cited in Goodwin-Groen, 1998, p. 3.

Avi-Yonah, R. 2000. Globalization, Tax Competition, and the Fiscal Crisis of the Welfare State », in Harvard Law Review, 113, pp.1575-1676.

Bermaerts, A. 1988, Bernaerts' Guide to the Law of the Sea: The 1982 United Nations Convention, Fairplay Publications.

Barco de Botero, C. and M. Smolka. 2000. «Challenges in implementing Colombia's Participación en Plusvalias', Land Lines », Lincoln Institute of Land Policy, March, pp. 4-7.

Bank for International Settlements (BIS). 1999. 69 $9^{\text {th }}$ Annual Report 1998-99.

2001. $71^{\text {st }}$ Annual Report 2000-01.

Boughton, J. M. 2001. Silent Revolution: the International Monetary Fund 1979-1989, IMF. Commission for Sustainable Development, 1995.

De Vries, M.G. 1976. The International Monetary Fund, 1966-1971: The System under Stress, 2 volumes, IMF.

Felix, D. 2001. 'Annual revenue from a Tobin tax under alternative tax rates', Conference papers, Halifax Initiative Conference on Taxing Currency Transactions: from Feasibility to Implementation, Vancouver, 4-6 October 2001, pp. 39-47.

Getubig, I., J Remenyi, and B. Quinones (eds.) 1997. Creating the Vision: Microfinancing the Poor in Asia-Pacific: Issues, Constraints and Capacity-building, Highlights of the BANK POOR '96 Workshop, Asia and Pacific Development Centre, Kuala Lumpur; cited Goodwin-Groen, 1998, p.3.

Gold, J. 1970. Special Drawing Rights: Character and Use, IMF Pamphlet Series No. 13, $2^{\text {nd }}$ ed., 1970, p. 28; cited in De Vries, 1976, volume 1, p. 188.

Goodwin-Groen, R. 1998. The Role of Commercial Banks in Microfinance: Asia-Pacific Region, Foundation for Development Cooperation, Brisbane.

Gurtner, B. 2002. 'International tax competition and tax evasion and the developing countries', Speaking Notes for the Friedrich Ebert Foundation Conference, New York, July 8-9, 2002, on Money Laundering and Tax Havens - The Hidden Billions for Development (typescript). Friedrich Ebert Stiftung.

Heimans, J. 2002. 'Multisectoral Global Funds as instruments for financing spending on global priorities', Excerpt of a discussion paper commissioned by the United Nations Secretariat Department of Economic and Social Affairs, March.

International Civil Aviation Organization. 2001. 'Aircraft engine emissions - ICAO's existing policies', Background information for the Colloquium on Environmental Aspects of Aviation, 1-11 April 2001. Montreal.

International Financial Statistics, 2001 Yearbook, IMF. 
Morduch, J. 1999. 'The microfinance promise', in Journal of Economic Literature, XXXVII, December, pp. 1569-1614.

OECD [Organization for Economic Cooperation and Development]. 2002. Proposed legal framework for exchange of information, available on OECD web site: www.oecd.org/daf/ctpa cited in Owens, 2002, p. 3.

Ostrom, E. 1990. Managing the Commons, Cambridge University Press.

Owens, J. 2002. The OECD work on tax havens', Paper for the Friedrich Ebert Foundation Conference, New York, July 8-9, 2002, on Money Laundering and Tax Havens - The Hidden Billions for Development, typescript. Friedrich Ebert Stiftung.

Pecoul, B., K Balasubramaniam and J. Love. 1999. 'Open Letter to the WTO member countries on TRIPS and access to health care technology', Médecins sans Frontières, Health Action International \& Consumer Project on Technology, December.

Sachs, J. 1999. 'Helping the world's poorest', in The Economist, 14 August 1999, pp. 16-22.

Schmidt, R. 1999. 'A feasible foreign exchange transactions tax', Paper presented to the North-South Institute, Ottawa, June.

. 2001. 'Efficient capital controls', in Journal of Economic Studies, 28(3), pp. 199-212.

Soros, G. 2002. On Globalization. Public Affairs Ltd, Oxford.

Spahn, P.B. 1996. 'The Tobin tax and exchange rate stability', in Finance and Development, 33, June, pp. 24-7.

2002. On the Feasibility of a Tax on Foreign Exchange Transactions, Report to the Federal Ministry for Economic Cooperation and Development, Bonn. February. Available from: www.wiwi.uni-frankfurt.de/professoren/spahn/tobintax

Tanzi, V. 1995. Taxation in an Integrating World, Brookings Institution.

The Economist. 23 November 2002, p. 59.

UN [United Nations]. 1997. World Economic and Social Survey 1997.

. 2001. Report to the Secretary-General of the High-level Panel on Financing for Development [the Zedillo Report], 25 June 2001.

Ul-Haq, M. et al. (eds.). 1996. The Tobin Tax: Coping with Financial Volatility. Oxford University Press, New York.

Uphoff, N. 1996, Learning from Gal Oya, IT Publications.

WHO [World Health Organization]. 2001. Macroeconomics and Health: Investing in Health for Economic Development, Report of the Commission on Macroeconomics and Health, Geneva, WHO.

World Bank. 1992. World Development Report 1992.

2000. World Development Report 1999/2000.

World Tourism Organization. 1998. Yearbook of Tourism Statistics, $50^{\text {th }}$ ed. 


\section{Policy Integration Department Working Papers prepared for the World Commission on the Social Dimension of Globalization}

No. 16 International finance: Meeting the needs of people in developing countries, José Guilherme Almeida dos Reis

No. 17 The gender dimensions of the globalization of production, Stephanie Barrientos, Naila Kabeer and Naomi Hossain

No. 18 Social exclusion in the context of globalization, Jan Breman

No. 19 Gender and globalization: A macroeconomic perspective, Çağatay Nilüfer and Ertük Korkurt

No. 20 Globalization, social exclusion, and work: with special reference to informal employment and gender, Marilyn Carr and Martha Chen

No. 21 Resources for social development, Anthony Clunies Ross

No. 22 Does the new international trade regime leave room for industrialization policies in the middle-income countries?, Alisa DiCaprio and Alice Amsden

No. 23 Social dimension of globalization in Latin America: Lessons from Bolivia and Chile, Alvaro García Hurtado

No. 24 Globalization: Social impact and policy actions: A partly annotated bibliography, Bernhard Gunter and Rolph van der Hoeven

No. 25 The social dimension of global production systems, Susan Hayter

No. 26 Reforming global economic and social governance:

a critical review of recent programmatic thinking, Jeremy Heimans

No. 27 Corporate social responsibility: An issues paper, Michael Hopkins

No. 28 Upgrading in global value chains, John Humphrey

No. 29 Implications of globalization and economic restructuring for skills development in Sub-Sahara Africa, Richard K. Johanson

No. 30 The outcome and impact of the main international commissions on development issues, Frédéric Lapeyre

No. 31 Globalization and structural adjustment as a development tool, Frédéric Lapeyre

No. 32 Globalization and perceptions of social inequality, Malte Luebker

No. 33 The changing structure of trade linked to global production systems: What are the policy implications?, William Milberg

No. 34 Corporate social responsibility: An overview of principles and practice, Jill Murray

No. 35 Inclusive development strategy in an era of globalization, Ignacy Sachs

No. 36 Social consequences of the globalization of the media and communications sector: Some strategic considerations, Seán Ó. Siochrú

No. 37 Globalization, history and international migration - A view from Latin America, Andrés Solimano

No. 38 Towards a different kind of globalization, or how the anti-globalizers view the world, Gijsbert van Liemt 